\title{
Differential Reelin-Induced Enhancement of NMDA and AMPA Receptor Activity in the Adult Hippocampus
}

\author{
Shenfeng Qiu, ${ }^{1}$ Lisa F. Zhao, ${ }^{1}$ Kimberly M. Korwek, ${ }^{3}$ and Edwin J. Weeber ${ }^{1,2,4}$ \\ Departments of ${ }^{1}$ Molecular Physiology and Biophysics and ${ }^{2}$ Pharmacology, ${ }^{3}$ Neuroscience Graduate Program, and ${ }^{4}$ Vanderbilt Kennedy Center for \\ Research on Human Development, Vanderbilt University Medical Center, Nashville, Tennessee 37232-0615
}

The developmental lamination of the hippocampus and other cortical structures requires a signaling cascade initiated by reelin and its receptors, apoER2 (apolipoprotein E receptor 2) and VLDLR (very-low-density lipoprotein receptor). However, the functional significance of continued reelin expression in the postnatal brain remains poorly understood. Here, we show that reelin application to adult mice hippocampal slices leads to enhanced glutamatergic transmission mediated by NMDA receptors (NMDARs) and AMPA receptors (AMPARs) through distinct mechanisms. Application of recombinant reelin enhanced NMDAR-mediated currents through postsynaptic mechanisms, as revealed by the variance-mean analysis of synaptic NMDAR currents, assessment of spontaneous miniature events, and the levels of NMDAR subunits at synaptic surface. In comparison, nonstationary fluctuation analysis of miniature AMPAR currents and quantification of synaptic surface proteins revealed that reelin-induced enhancement of AMPAR responses was mediated by increased AMPAR numbers. Reelin enhancement of synaptic NMDAR currents was abolished when receptor-associated protein (RAP) or the Src inhibitor 4-amino-5-(4-methylphenyl)-7-(t-butyl)pyrazolo[3,4-d]-pyrimidine (PP1) was bath applied and was abrogated by including PP1 in the recording electrodes. In comparison, including RAP or an inactive PP1 analog PP3 in the recording electrode was without effect. Interestingly, the increased AMPAR response after reelin application was not blocked by PP1 but was blocked by the phosphoinositide-3' kinase (PI3K) inhibitors wortmannin and LY294002 [2-(4-morpholinyl)-8-phenyl-1(4H)-benzopyran-4-one hydrochloride]. Furthermore, reelin-induced, PI3K-dependent AMPAR surface insertion was also observed in cultured hippocampal neurons. Together, these results reveal a differential functional coupling of reelin signaling with NMDAR and AMPAR function and define a novel mechanism for controlling synaptic strength and plasticity in the adult hippocampus.

Key words: apolipoprotein receptors; long-term potentiation; Src tyrosine kinase; phosphoinositide-3 kinase; synaptic plasticity; receptor trafficking

\section{Introduction}

Reelin-mediated signaling through apolipoprotein E receptor 2 (apoER2) and very-low-density lipoprotein receptor (VLDLR) dictates developmental lamination of principal and intrinsic neurons and the positioning of innervating fibers in the hippocampus (Del Rio et al., 1997; D’Arcangelo et al., 1999; Trommsdorff et al., 1999; Benhayon et al., 2003; Yabut et al., 2006). Transduction of reelin signaling occurs through interaction of disabled-1 (Dab1) with the intracellular NPxY motif of these receptors, resulting in tyrosine phosphorylation of Dab1, activation of the SFKs (Src family nonreceptor tyrosine kinases), and an ensuing signaling cascade that leads to proper neuronal migration (Howell et al., 1997, 1999a; Trommsdorff et al., 1998; Arnaud et al.,

\footnotetext{
Received June 19, 2006; revised Nov. 1, 2006; accepted Nov. 1, 2006.

This work was supported by National Institutes of Health/National Institute on Aging Grant 1 R01 AG022574-01 A1. We thank Drs. Joachim Herz and Uwe Beffert (University of Texas Southwestern) for the generous gift of the stably transfected reelin-expressing HEK293 cells and the apoER2 antibody. We thank Danny Winder (Vanderbilt University Medical (enter) for critical reading of an early version of this manuscript.

Correspondence should be addressed to Dr. Edwin J. Weeber, Department of Molecular Physiology and Biophysics, 754 Robinson Research Building, Vanderbilt University Medical Center, Nashville, TN 37232-0615. E-mail: edwin.j.weeber@vanderbilt.edu.

DOI:10.1523/JNEUROSCI.2561-06.2006

Copyright $\odot 2006$ Society for Neuroscience $\quad$ 0270-6474/06/2612943-13\$15.00/0
}

2003; Bock and Herz, 2003). Considering the fact that reelin is also abundantly expressed by interneurons, and all of the downstream signaling components exist in the postnatal hippocampus (Alcantara et al., 1998; Pesold et al., 1998; Abraham and Meyer, 2003; Zhao et al., 2004), it is intriguing to know whether reelinmediated signaling plays a physiological role in adult brain function.

We have shown previously that reelin signaling enhances tetanus-induced long term potentiation (LTP) in CA1 region. In addition, adult mice lacking apoER2 or VLDLR showed impaired memory performance (Weeber et al., 2002). It was also recently found that the modulatory effects of reelin on synaptic plasticity and memory require the presence of an alternatively spliced intracellular domain of apoER2 encoded by exon 19, through which the postsynaptic scaffolding protein postsynaptic density-95 (PSD-95) is associated (Beffert et al., 2005). Moreover, both apoER2 and NMDA-type glutamate receptors (NMDARs) reside in CA1 postsynaptic densities, and reelin signaling enhances NMDAR-mediated whole-cell currents (Beffert et al., 2005). Given that two major forms of CA1 plasticity, LTP and long-term depression (LTD), require NMDAR activity, which can be modulated by Src-dependent tyrosine phosphorylation of NMDAR 2A subunits NR2A and NR2B (Lau and Huganir, 1995; 
Yu et al., 1997; Lu et al., 1998; Salter and Kalia, 2004), an altered tyrosine phosphorylation of NMDARs by Src downstream of reelin signaling could have a profound effect on CA1 synaptic transmission and plasticity. To date, a causative connection between Src and NMDAR activity in response to reelin has not been established in vivo. Moreover, it is not known whether AMPARmediated synaptic transmission could be affected by reelin signaling.

Recent studies indicate that reelin is also required for normal development of dendritic structures (Niu et al., 2004), developmental maturation of NMDARs (Sinagra et al., 2005), and enhancement of glutamate-induced NMDAR activities (Chen et al., 2005). These studies suggest a potential broader functional connection of reelin signaling with glutamatergic function in the adult brain. Here, we provide experimental evidence demonstrating that reelin-induced signaling is coupled with enhanced synaptic NMDAR response through Src-dependent postsynaptic mechanisms. In addition, we have uncovered that reelin signaling via a phosphoinositide- $3^{\prime}$ kinase (PI3K)-dependent mechanism enhances synaptic transmission by facilitating surface insertion of AMPA receptors, a process that is independent of Src activity. Thus, in addition to its well established role during embryonic neuronal development, reelin signaling could also play an important physiological role in synaptic transmission and plasticity in the adult hippocampus.

\section{Materials and Methods}

Acute hippocampal slice preparation and drug treatment. The $\mathrm{B} 6 \mathrm{C} 3 \mathrm{Fe}$ $\left(\mathrm{a} / \mathrm{a}-\operatorname{Reln}^{\mathrm{r} l /+}\right.$ ) strain mice were obtained from The Jackson Laboratory (Bar Harbor, ME). These mice were on the mixed background of B6 and $\mathrm{C} 3 \mathrm{H}$ strains and carried both alleles of the RELN gene. Animal care and use protocol was according to National Institutes of Health guidelines and approved by the Institutional Animal Care and Use Committee of Vanderbilt University. Young adult mice (4-6 weeks of age; male or female) were killed by cervical dislocation, and the brains were quickly removed. Horizontal sections $(300-400 \mu \mathrm{m})$ were made using a vibratome in sucrose cutting solution [containing the following (in $\mathrm{mM}$ ): 110 sucrose, $6 \mathrm{NaCl}, 3 \mathrm{KCl}, 26 \mathrm{NaHCO}_{3}, 1.25 \mathrm{NaH}_{2} \mathrm{PO}_{4}, 7 \mathrm{MgCl}_{2}, 0.5$ $\mathrm{CaCl}_{2}, 0.6$ sodium ascorbate, and 10 glucose, $\mathrm{pH}$ 7.3-7.4]. The slices were transferred to artificial CSF (ACSF) [containing the following (in $\mathrm{mM}$ ): $125 \mathrm{NaCl}, 2.5 \mathrm{KCl}, 1.25 \mathrm{NaH}_{2} \mathrm{PO}_{4}, 26 \mathrm{NaHCO}_{3}, 1.2 \mathrm{MgCl}_{2}, 2.0 \mathrm{CaCl}_{2}$, and 10 glucose, $\mathrm{pH} 7.3-7.4]$ and bubbled with $95 \% \mathrm{O}_{2} / 5 \% \mathrm{CO}_{2}$. Slices were allowed to recover at room temperature for at least $1.5 \mathrm{~h}$ before being switched to the recording chamber. Bicuculline $(20 \mu \mathrm{M})$ was included in the perfusate when slices were used for whole-cell recordings. Where necessary, a surgical cut was made at the CA3-CA1 border to role out potential somatodendritic effects on CA3 by reelin.

Recombinant reelin was produced by using HEK293 (human embryonic kidney cell line) cells that are stably transfected with the full-length reelin construct pCrl vector (D'Arcangelo et al., 1997). The expression of GST-RAP fusion protein was obtained by using DH5 $\alpha$ cells carrying the GST-RAP vector construct (provided by Dr. G. Bu, Washington University School of Medicine, St. Louis, MO) (Zhuo et al., 2000). The preparation and purification of reelin and GST-RAP and the preparation of mock-conditioned medium (the parallel column fraction as reelin medium) were essentially as described previously (Sinagra et al., 2005). TTX, CNQX, D-2-amino-5-phosphonopentanoic acid (D-AP5), wortmannin, 2-(4-morpholinyl)-8-phenyl-1(4H)-benzopyran-4-one hydrochloride (LY294002), and bicuculline were purchased from Tocris Bioscience (Ellisville, MO). The Src inhibitor 4-amino-5-(4methylphenyl)-7-(t-butyl)pyrazolo[3,4-d]pyrimidine (PP1) was purchased from Calbiochem (La Jolla, CA).

Electrophysiology. Field EPSPs (fEPSPs) in response to a biphasic stimulus pulse (1-15 V; $100 \mu$ s duration; $0.05 \mathrm{~Hz})$ were recorded in CA1 stratum radiatum using glass micropipettes filled with $3 \mathrm{M} \mathrm{NaCl}(1-2 \mathrm{M} \Omega$ electrical resistance) at $\sim 30^{\circ} \mathrm{C}$. Stimulating electrodes were constructed from twisted insulated stainless-steel wire and placed in the stratum radiatum close to the $\mathrm{CA} 3$ region. Stimulating pulses were generated by the Digidata 1322A interface (Molecular Devices, Sunnyvale, CA) and a stimulus isolator (model 2200; A-M Systems, Sequim, WA) under control of Clampex 9.0 software (Molecular Devices). fEPSPs were amplified using a differential amplifier (model 1800; A-M Systems), filtered at 1 $\mathrm{kHz}$, and digitized at $10 \mathrm{kHz}$. Baseline stimulus intensity was set at the level that elicits $\sim 50 \%$ maximum fEPSP response. Stable baseline responses were monitored for $20 \mathrm{~min}$ before drug application.

Spontaneous or synaptically evoked whole-cell responses of CA1 pyramidal neurons were recorded at room temperature $\left(22-24^{\circ} \mathrm{C}\right)$ using an EPC10 double amplifier (Heka Elektronik, Lambrecht/Pfalz, Germany) with the aid of differential interference contrast microscopy (Leica DMLSFA; Leica Microsystems, Wetzlar, Germany). The patch electrodes (4-7 M $\Omega$ ) were filled with a solution containing the following (in $\mathrm{mm}$ ): 117 Cs gluconate, 10 tetraethylammonium-Cl, 10 HEPES, $8 \mathrm{NaCl}, 5$ lidocaine $N$-ethyl bromide- $\mathrm{Cl}, 4 \mathrm{Mg}^{2+}$-ATP, $2.5 \mathrm{CsCl}, 0.3 \mathrm{Na}_{3} \mathrm{GTP}$, and 0.2 EGTA, and adjusted to $\mathrm{pH} 7.2,280-290 \mathrm{mOsm}$. CA1 pyramidal neurons were voltage clamped at $-65 \mathrm{mV}$ in whole-cell configuration for at least $10 \mathrm{~min}$ to achieve stable holding currents. Series resistance $(8-15$ $\mathrm{M} \Omega$ ) was monitored by applying $5 \mathrm{~ms}$ hyperpolarizing voltage steps. Experiments were terminated if serial resistance or input resistance changed by $>15 \%$. To measure spontaneous miniature EPSCs (mEPSCs), slices were preincubated with $20 \mu \mathrm{M}$ bicuculline and $1 \mu \mathrm{M}$ TTX for $30 \mathrm{~min}$, and experiments were performed in the continued presence of these chemicals. To determine NMDAR-mediated miniature events, slices were perfused in $\mathrm{Mg}^{2+}$-free ACSF to record events that were produced by both AMPARs and NMDARs and then switched to the same $\mathrm{Mg}^{2+}$-free ACSF supplemented with $100 \mu \mathrm{M}$ D-AP5 to reveal the AMPAR component. The averaged miniature NMDAR-mediated EPSC $\left(\right.$ EPSC $\left._{\mathrm{NMDA}}\right)$ was obtained by digital subtraction of the averaged mEPSCs under these two different conditions.

Peak-scaled nonstationary fluctuation analysis of AMPAR-mediated miniature EPSCs $\left(\mathrm{mEPSC}_{\mathrm{AMPA}} \mathrm{s}\right)$ was performed essentially as described previously (Traynelis et al., 1993; Benke et al., 1998). Briefly, mEPSC $_{\text {AMPA }}$ was detected using a sliding template algorithm in Clampfit 9.0 (Molecular Devices). The events were visually inspected, aligned by their point of steepest rise, and then averaged. Mean $\mathrm{mEPSC}_{\mathrm{AMPA}}$ was peak scaled to each individual trace and was subtracted from it to obtain the difference. The variance of the decay phase of the difference currents was calculated and plotted against the mean IEPSC $_{\mathrm{AMPA}}$ after binning. AMPAR single-channel current and numbers were estimated by fitting the first $50 \%$ data points back-calculated from the end-of-decay baseline to the following equation: $\sigma^{2}=i I-I^{2} / N+\sigma_{\mathrm{b}}{ }^{2}$, where $\sigma^{2}$ is the variance, $i$ is the weighted-mean single-channel current, $I$ is the mean current, $N$ is the number of AMPAR channels opening at the peak of the mean current, and $\sigma_{\mathrm{b}}{ }^{2}$ is the variance of the baseline noise. The singlechannel conductance $(\gamma)$ is therefore $\gamma=i / V$, where $V$ denotes driving force, which is the holding potential, assuming a reversal potential of 0 $\mathrm{mV}$ for AMPAR channels.

Monosynaptically evoked whole-cell responses, as verified by their high synchrony across varying stimulus intensities, were recorded at either $-65 \mathrm{mV}$ or $+40 \mathrm{mV}$ in response to stimulus driven by a Master-8-cp stimulator (A.M.P.I., Jerusalem, Israel) and delivered through a bipolar tungsten electrode (FHC, Bowdoinham, ME) to Schaffer collateral fibers. The stimulus intensity was adjusted to just above the sharp threshold for activation of a monosynaptic response. To obtain NMDAR-mediated whole-cell currents, neurons were clamped at $+40 \mathrm{mV}$ in the presence of $10 \mu \mathrm{M}$ CNQX, and the responses were confirmed by washing in $100 \mu \mathrm{M}$ D-AP5 before termination of experiments. Electric signals were digitized by either the EPC10 or Digidata $1322 \mathrm{~A}$ at $10 \mathrm{kHz}$ and filtered at $2 \mathrm{kHz}$, stored on a personal computer, and analyzed offline.

Immunoprecipitation and Western blotting. Acutely prepared slices $(300-400 \mu \mathrm{m})$ from 4- to 6-week-old mice were allowed to recover in ACSF for $1 \mathrm{~h}$, and then three to four slices were pooled in one group. Care was taken to ensure that each group had slices of similar septotemporal levels. Reelin ( 5 or $20 \mathrm{~nm}$ ) was then applied in the bathing ACSF, and slices were incubated at $32^{\circ} \mathrm{C}$ for $15 \mathrm{~min}$ (for detection of NMDAR subunit phosphorylation) or $60 \mathrm{~min}$ (for detection of AMPAR subunit phos- 
phorylation and receptor trafficking). CA1 regions were then dissected out and flash frozen on dry ice. The tissues were then sonicated in $300 \mu \mathrm{l}$ of immunoprecipitation (IP) buffer containing 50 mм Tris- $\mathrm{HCl}, \mathrm{pH}$ 7.4, $150 \mathrm{~mm} \mathrm{NaCl}, 1 \mathrm{~mm}$ EDTA, $50 \mathrm{~mm} \mathrm{NaF}, 100 \mu \mathrm{m}$ leupeptin, $1 \mu \mathrm{m}$ pepstatin, $10 \mu \mathrm{g} / \mathrm{ml}$ aprotinin, $10 \mu \mathrm{g} / \mathrm{ml}$ bacitracin, $1 \mathrm{~mm}$ PMSF, $1 \mathrm{~mm} \mathrm{Na} \mathrm{VO}_{4}$, and $1 \%$ Nonidet $\mathrm{P} 40$. Protein contents of homogenates were determined using Bradford assay (Bio-Rad, Hercules, CA).

For Western blot analysis, $10 \mu \mathrm{g}$ of protein was resolved by $8 \%$ SDSPAGE. For immunoprecipitation experiments, the lysate was incubated with $30 \mu \mathrm{l}$ of 1:1 protein A/Sepharose CL-4B (GE Healthcare, Piscataway, $\mathrm{NJ}$ ) (in $0.01 \mathrm{M} \mathrm{PBS}, \mathrm{pH} 7.4$ ) for $1 \mathrm{~h}$ at $4^{\circ} \mathrm{C}$ to preclear nonspecific binding to protein A. In the meanwhile, 5-10 $\mu \mathrm{g}$ of primary antibodies were incubated with $25 \mu \mathrm{l}$ of protein A magnetic beads (New England Biolabs, Boston, MA) for $1 \mathrm{~h}$ at $4^{\circ} \mathrm{C}$ with constant agitation. The magnetic beads were then washed three times with IP buffer, added to the precleared CA1 tissue lysates, and incubated at $4^{\circ} \mathrm{C}$ for $2 \mathrm{~h}$. The immunocomplex was then washed twice with IP buffer, the proteins were eluted using Laemmli $2 \times$ buffer and separated by SDS-PAGE by running through $9 \%$ or 4-20\% gradient SDS-polyacrylamide gels. The proteins were then transferred to polyvinylidene difluoride (PVDF) membranes (Immobilon-P; Millipore, Billerica, MA) and incubated for $2 \mathrm{~h}$ at room temperature (RT) with monoclonal anti-phosphotyrosine (pY) antibody (4G10) or rabbit antibodies against apoER2 (provided by U. Beffert), PSD-95, NR1, NR2A, NR2B, or Src. The membranes were then washed extensively in $0.01 \mathrm{M}$ PBS-Tween 20 and incubated for $1 \mathrm{~h}$ at RT with HRP-conjugated anti-mouse or anti-rabbit IgG (Promega, Madison, WI) and developed using enhanced chemiluminescence (ECL) method. Rabbit anti-NR2A, anti-NR2B, anti-glutamate receptor 1 (GluR1) (p-Ser831 or p-Ser845), and anti-Src antibodies were purchased from Millipore. Rabbit anti-NR1 and anti-Dab1 antibodies were obtained from Millipore. The dilution of antibodies was between 1:1000 and 1:5000. Optical density of immunoreactive bands was quantified by densitometry using Quantity One software (Bio-Rad).

Cell surface protein biotinylation and subcellular fractionation. Acute slices treated with reelin or mock for 60 min were biotinylated with 0.25 $\mathrm{mg} / \mathrm{ml}$ sulfo-NHS-S-S-biotin (Pierce Biotechnology, Rockford, IL) for $30 \mathrm{~min}$ at $4^{\circ} \mathrm{C}$, using a Pinpoint cell surface protein isolation kit, similar to that described previously for biotinylation in hippocampal slices (Broutman and Baudry, 2001). CA1 regions were dissected out and sonicated in cold homogenization buffer containing 4 mM HEPES, $320 \mathrm{~mm}$ sucrose, and protease inhibitor cocktail (Sigma, St. Louis, MO). The homogenates were centrifuged at $1500 \times g$ for $10 \mathrm{~min}$, and the supernatant was collected and centrifuged at $16,000 \times g$ for 20 min to yield a pellet containing the crude synaptosome fraction. This crude synaptosome fraction was then lysed and resuspended in ice-cold water containing protease inhibitor cocktail. Total synaptosome proteins were then determined by Western blot analysis using specific glutamate receptor antibodies. Alternatively, after additional centrifugation at $48,000 \times g$ for $30 \mathrm{~min}$, the pellets that contain synaptic membranes were collected, resuspended in IP buffer at a concentration of $0.1 \mathrm{mg} / \mathrm{ml}$, mixed with immobilized NeutrAvidin beads (Pierce Biotechnology), and rotated for $2 \mathrm{~h}$ at $4^{\circ} \mathrm{C}$. The beads were washed three times in IP buffer and treated with $2 \times$ Laemmli buffer supplemented with $50 \mathrm{~mm}$ DTT to elute the biotinylated proteins. The biotinylated proteins were separated by SDSPAGE, transferred to PVDF membranes, and immunoblotted with NR1, NR2A, NR2B, GluR1, and GluR2/3 antibodies, followed by HRPconjugated secondary antibodies and ECL detection, similar to that described above.

Hippocampal neuronal culture, immunocytochemistry, and image analysis. Hippocampal neuronal cultures were prepared from 16- to 17-d-old embryonic mice. Briefly, the fetal brains were dissected out, and hippocampi were collected and digested in HBSS containing $0.5 \mathrm{mg} / \mathrm{ml}$ papain at $37^{\circ} \mathrm{C}$ for $20 \mathrm{~min}$. The hippocampi were gently triturated in HBSS with a glass micropipette, and the neurons were seeded on poly-Dlysine-coated $12 \mathrm{~mm}$ coverslips at $10,000 \mathrm{cells} / \mathrm{cm}^{2}$ and grown in Neurobasal medium supplemented with B27. Every $5 \mathrm{~d}$ after plating, one-half of the medium was replaced with fresh plating medium containing $10 \mu \mathrm{M}$ cytosine arabinoside. Experiments were conducted between 14 and $20 \mathrm{~d}$ after plating. To label newly inserted membrane surface GluR1s
(sGluR1s), a protocol similar to that described by Man et al. (2003) was adopted. Neurons were incubated at $4^{\circ} \mathrm{C}$ with an anti-GluR1 N-terminal antibody (N-GluR1; Calbiochem) diluted in fresh Neurobasal medium for $30 \mathrm{~min}$, followed by a $45 \mathrm{~min}$ incubation with nonconjugated antirabbit IgG antibody. Neurons were then washed three times in Neurobasal medium and returned to their original growth medium. Reelin and/or other drugs were added for $12 \mathrm{~h}$. Neurons were then fixed under nonpermeabilized conditions at $4^{\circ} \mathrm{C}$ for $20 \mathrm{~min}$ in $0.1 \mathrm{M} \mathrm{PBS}$ containing $4 \%$ paraformaldehyde and $4 \%$ sucrose. The neurons were then permeabilized for $20 \mathrm{~min}$ in $0.2 \%$ Triton X-100, blocked with $0.01 \mathrm{~m}$ PBS containing $10 \%$ normal donkey serum, and incubated overnight with primary antibodies (N-GluR1; 1:500 dilution), followed by a $2 \mathrm{~h}$ incubation with FITC-conjugated donkey secondary anti-rabbit IgG (Jackson ImmunoResearch, West Grove, PA).

Digital images were taken with a Zeiss (Thornwood, NY) LSM510 confocal microscope using a $40 \times$ oil-immersion lens (numerical aperture, 1.3). All images from the same experiment were acquired with identical settings for laser power, photomultiplier gain, and offset, and a fixed pinhole size of one Airy unit. Images were encoded to analyze blindly using MetaMorph software (Molecular Devices). Thresholds for GluR1 immunostaining were chosen such that all visually recognizable punctate labeling was included for analysis with minimum selection of the pixels surrounding the puncta. At least 10 different neurons were analyzed per group, and the sections of $50-100 \mu \mathrm{m}$ of all of the primary dendrites were counted to determine the number of GluR1-positive puncta. Each experiment was repeated in four to five cultures.

Data analysis. The slope of fEPSP was measured using a $1 \mathrm{~ms}$ time interval after the fiber volley. The amplitude of whole-cell EPSCs was defined as the averaged 2-4 ms value around the peak minus the stable holding current immediately preceding the stimulus artifact and was quantified by averaging 12 consecutive traces during a $1 \mathrm{~min}$ time period. Detection and analysis of mEPSCs were done using either Clampfit 9.0 or Minianalysis software (Synaptosoft, Atlanta, GA). Each detected event was confirmed by visual inspection.

For the statistical analysis, data were represented by mean \pm SEM. An unpaired Student's $t$ test, one-way ANOVA (with post hoc Student-Newman-Keuls test when overall significance was achieved), or two-way ANOVA analysis was performed when data passed a normality test. For the comparison of cumulative histogram of mEPSC amplitudes, a Kolmogorov-Smirnov test was used. Significance was assigned for all tests at $p<0.05$.

\section{Results}

\section{Reelin enhances pairing-induced LTP of synaptic responses}

It has been well established that reelin signaling is linearly transmitted through apoER2, VLDLR, and the intracellular adaptor protein Dab1, resulting in activation of Src family tyrosine kinases (Howell et al., 1997; D'Arcangelo et al., 1999; Hiesberger et al., 1999; Arnaud et al., 2003). We have shown previously that bath perfusion of reelin increases the magnitude of tetanusinduced LTP of field potentials in CA1 (Weeber et al., 2002), presumably as a result of Src activation and enhanced NMDAR function to facilitate LTP induction. To expand these findings at cellular levels and further investigate the role of reelin in synaptic plasticity, we tested whether reelin affects pairing-induced LTP of synaptically evoked whole-cell currents of CA1 neurons. CA1 pyramidal neurons were voltage clamped at $-65 \mathrm{mV}$, and reelin [ $5 \mathrm{nM}$, a concentration that is equivalent to 10 times the estimated $K_{\mathrm{d}}$ of reelin for VLDLR and apoER2 (Hiesberger et al., 1999)] was applied for $10 \mathrm{~min}$. Neurons were then depolarized to $-10 \mathrm{mV}$ while 120 stimuli were delivered at $1 \mathrm{~Hz}$. Figure 1 shows that this pairing protocol resulted in a $45.5 \pm 9.1 \%$ increase in EPSC amplitude at $1 \mathrm{~h}$ after pairing in control slices, which is significantly less than the pairing-induced increase in the presence of reelin $(141.9 \pm 9.9 \% ; t$ test; $n=7 ; p<0.001)$. Therefore, synaptic plasticity of CA1 synapses is dramatically enhanced as a result of reelin application. 
Reelin enhances synaptic NMDAR and AMPAR currents without changing short-term plasticity

To further verify a causative connection between reelin application and enhanced synaptic plasticity, we examined the effects of reelin on synaptic transmission mediated by NMDAR and AMPAR separately in adult hippocampal CA1. We applied 5 nM recombinant reelin through bath perfusion and recorded synaptically evoked EPSC $_{\mathrm{NMDA}}$ under voltage-clamped conditions ( $+40 \mathrm{mV}$ with $20 \mu \mathrm{M}$ bicuculline and $10 \mu \mathrm{M}$ CNQX). This EPSC $_{\text {NMDA }}$ was confirmed by complete abolishment after addition of $100 \mu \mathrm{M}$ D-AP5 after completion of the experiments (data not shown). We observed an immediate increase of EPSC $_{\mathrm{NMDA}}$ within 10 min of reelin but not mock application, which lasted for at least $1 \mathrm{~h}$ in the continued presence of reelin (Fig. 2A) (percentage of baseline at $1 \mathrm{~h}$ : reelin, $124.7 \pm 5.8 \%$; mock, $102.3 \pm 7.6 \%$; $\left.n=8 ; F_{(2,23)}=6.75 ; p<0.05\right)$. This reelininduced increase of EPSC $_{\mathrm{NMDA}}$ was concentration dependent, because $0.5 \mathrm{~nm}$ reelin was without effect (data not shown).

Although a significant enhancement of LTP and an increase of EPSC $_{\text {NMDA }}$ occurred after reelin treatment, no change of paired-pulse facilitation of AMPARmediated fEPSPs was observed across various interpulse intervals ranging from 20 to $300 \mathrm{~ms}$ after $1 \mathrm{~h}$ of reelin application (Fig. $2 B)(n=5$ slices from 5 mice; $p>$ 0.05 for the effect of reelin; two-way ANOVA). In addition, we tested pairedpulse responses of EPSC $_{\mathrm{AMPA}}$ across various interpulse intervals (50-150 ms), and again no change was observed after a $1 \mathrm{~h}$ application of $5 \mathrm{~nm}$ reelin (Fig. $2 C)(n=6 ; p>0.05$ for the effect of reelin; two-way ANOVA), suggesting that short-term plasticity is not likely altered by reelin application.

In light of the dramatic effects of reelin on synaptic NMDAR currents, we sought to determine whether AMPAR-mediated responses can be altered by reelin application. We found that $5 \mathrm{nM}$ reelin consistently induced a delayed increase of fEPSP that started to develop at $\sim 25 \mathrm{~min}$ and peaked at $1 \mathrm{~h}$ after reelin application (data not shown). At the whole-cell level, reelin application also increased AMPAR-mediated synaptic currents under voltage-clamped conditions $(-65 \mathrm{mV}$ ) (Fig. $2 \mathrm{D}$ ) with a time course similar to that of the fEPSP slope, suggesting that enhanced AMPAR responses were not a result of increased NMDAR activity. In addition, increasing reelin concentration to $20 \mathrm{~nm}$ shortened the latency and increased the magnitude of potentiation of AMPAR whole-cell currents. Therefore, reelin application enhances synaptic currents mediated by both NMDARs and AMPARs.

\section{Postsynaptic mechanisms of reelin enhancement of NMDAR currents}

The ability of reelin to potentiate CA1 glutamatergic responses raises the question of the synaptic locus of reelin action. We have recently shown that one of the reelin receptors, apoER2, is present postsynaptically and forms a functional complex with NMDARs in CA1 (Beffert et al., 2005). However, it is not known whether apoER2 also contributes to presynaptic functions. We further investigated the synaptic locus of reelin enhancement of NMDAR function by first examining EEPSC $_{\mathrm{NMDA}}$. We perfused hippocampal slices (CA3 removed) with $\mathrm{Mg}^{2+}$-free ACSF in the presence of $1 \mu \mathrm{M}$ TTX and recorded mEPSCs that were generated by both AMPARs and NMDARs. Recordings were continued after reelin or mock application for an additional $20 \mathrm{~min}$. Slices were then perfused with additional $100 \mu \mathrm{M}$ D-AP5 to obtain the $\mathrm{mEPSC}_{\mathrm{AMPA}}$. The averaged $\mathrm{mEPSC}_{\mathrm{NMDA}}$ before and after reelin or mock was then determined by digital subtraction of averaged mEPSC $_{\mathrm{AMPA}}$ of a $30 \mathrm{~s}$ epoch from the averaged compound mEPSCs before and after reelin or mock application. The derivation of mEPSC $_{\text {NMDA }}$ is illustrated in Figure $3 A, B$. In 13 cells treated with mock, mEPSC $_{\mathrm{NMDA}}$ was not significantly changed compared with that before mock treatment (Fig. $3 C)(p>0.05$; paired $t$ test). In contrast, a significantly larger $\mathrm{mEPSC}_{\mathrm{NMDA}}$ amplitude was obtained after reelin treatment (Fig. $3 C)(p<0.001$; $n=18$; paired $t$ test). There was no change of the compound mEPSC event frequency after sequential addition of mock or reelin (data not shown). 
A

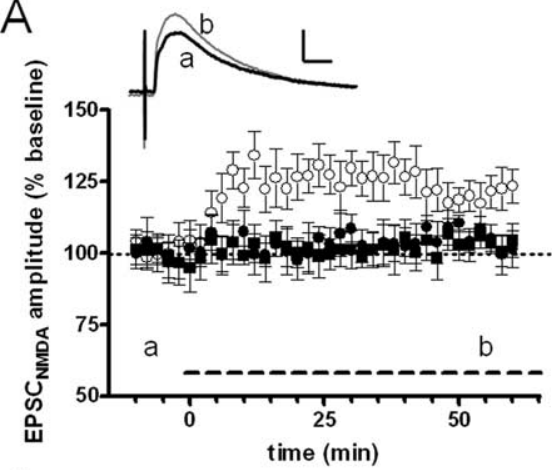

C

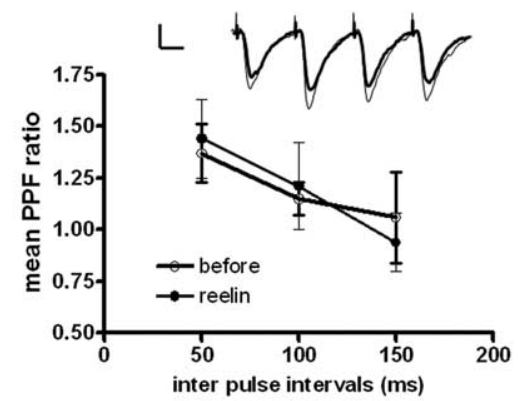

B

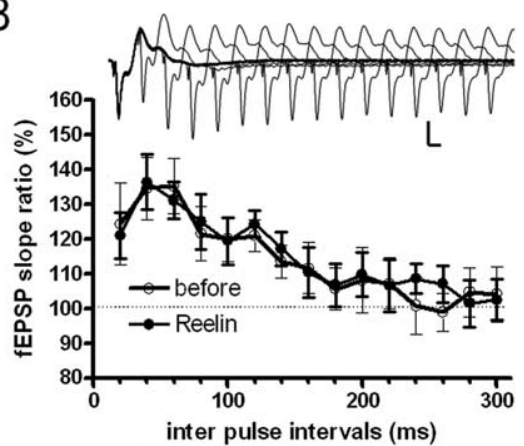

\section{D}

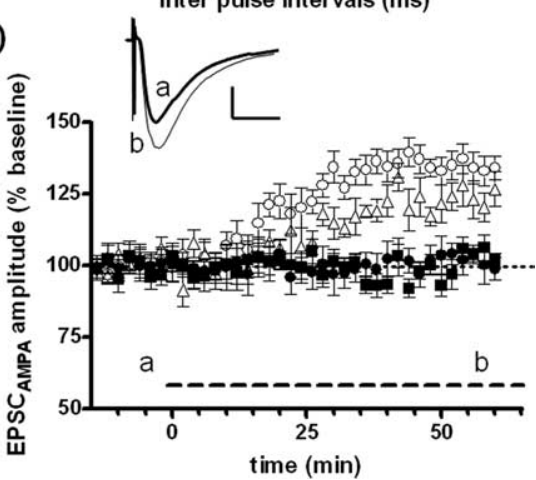

Herz, 2003), we examined the level of Src that is associated with PSD-95 through immunoprecipitation with PSD-95 antibody followed by immunoblotting with Src antibody. Reelin treatment significantly increases the amount of Src that is associated with PSD-95 protein by approximately threefold (Fig. $4 B)(n=4$; quantification not shown), suggesting that Src is dynamically recruited to the PSD-95 signaling complex after reelin application.

Given that increased tyrosine phosphorylation has been seen in both NR2A (Beffert et al., 2005) and NR2B (Chen et al., 2005) subunits after reelin application, we tested whether this increase in tyrosine phosphorylation is reelin receptor and Src dependent. The tyrosine phosphorylation of the adaptor protein Dab1 was also examined, because it is increased after reelin binding to its receptors (Hiesberger et al., 1999; Arnaud et al., 2003; Benhayon et al., 2003; Bock and Herz, 2003). The proteins NR2A, NR2B, and Dab1 were first immunoprecipitated and then immunoblotted with the phosphotyrosine antibody $4 \mathrm{G} 10$. Figure $4 C$ shows that a significant increase in CA1 pY immunoreactivity of Dab1 occurred after $15 \mathrm{~min}$ of $5 \mathrm{~nm}$ reelin application $\left(221.2 \pm 14.5 \%\right.$ of control; $F_{(5,23)}=$ $19.24 ; p<0.001)$, which was completely blocked by either $10 \mu \mathrm{M}$ PP1 (89.9 $\pm 7.2 \%$; $n=4 ; p>0.05)$ or $20 \mu \mathrm{M}$ GST-RAP (96.4 $\pm 7.5 \% ; n=4 ; p>0.05)$ but not by $100 \mu \mathrm{M} \mathrm{D}-\mathrm{AP} 5$ (188.7 $\pm 11.2 \%$ of baseline; $\left.F_{(5,17)}=16.2 ; p<0.001\right)$. In addition,

To further verify that synaptic NMDAR response was increased as a result of postsynaptic effects of reelin, we analyzed the coefficient of variation (CV) of synaptically evoked NMDAR whole current. In these experiments, CA3 region was surgically removed to eliminate any potential effects of reelin on CA3 somatodendritic regions. According to binomial models of synaptic transmission, $1 / \mathrm{CV}^{2}$ is determined only by properties of presynaptic release and provides an empirical tool for comparing locus of synaptic action (Bolshakov and Siegelbaum, 1994; Frerking et al., 2001). When $1 / \mathrm{CV}^{2}$ ratios were plotted versus mean EPSC $_{\mathrm{NMDA}}$ ratios before and after a 30 min reelin application in nine experiments, no correlation was established (Fig. 3D) (Spearman's test; $r=0.31 ; p=0.4$ ). The $1 / \mathrm{CV}^{2}$ ratios remain relatively unchanged across varying mean EPSC $_{\mathrm{NMDA}}$ ratios, confirming our hypothesis that reelin is activating through a postsynaptic mechanism in CA1 to enhance NMDAR activity.

\section{Reelin signaling leads to Src-dependent phosphorylation of NMDAR subunits}

It has been shown previously that reelin signaling components, including apoER2 and NMDA receptor subunits, are physically associated with PSD-95 protein in transfected cell lines as well as hippocampal tissues (Beffert et al., 2005; Hoe et al., 2006). These results were reproducible in our slice preparations using only CA1 tissues (Fig. 4A). In addition, based on the fact that Src, PSD-95, and NMDARs form a complex, and Src is activated after reelin application (Lei et al., 2002; Arnaud et al., 2003; Bock and both pY of NR2A $\left(168.4 \pm 7.3 \%\right.$ of baseline; $F_{(5,17)}=18.4 ; p<$ $0.001)$ and NR2B $\left(191.2 \pm 13 \% ; F_{(5,17)}=22.4 ; p<0.001\right)$ were significantly increased over the baseline immunoreactivity after reelin application and were completely suppressed by either PP1 $(91.5 \pm 5.5 \%$ for NR2A; $83.1 \pm 7.2 \%$ for NR2B; $n=5$; compared with baseline levels, $p>0.05$ for both) or GST-RAP (104.3 \pm $4.1 \%$ for NR2A; $95.6 \pm 5.3 \%$ for NR2B; $n=4 ; p>0.05$ for both). To verify that the same amount of proteins from each group were immunoprecipitated, we used Western blot to detect the immunoprecipitated Dab1, NR2A, and NR2B in three separate experiments. The representative blots for each protein was shown in Figure $4 C$. No change of immunoreactivity across the groups for each protein was detected ( $p>0.05 ; n=3$ for each protein; data not shown). Therefore, our results confirmed that increased tyrosine phosphorylation of NMDAR subunits was downstream to increased Src activity as a result of reelin acting on its receptors.

\section{Reelin signaling increases synaptic targeting of AMPAR subunits but not NMDAR subunits}

The increased tyrosine phosphorylation of NMDAR subunits may completely account for the enhanced mEPSC $_{\mathrm{NMDA}}$ and synaptic whole-cell currents. Alternatively, increased NMDAR currents may be partly attributable to increased NMDAR trafficking to postsynaptic sites, as happens during certain forms of synaptic activity (Lan et al., 2001; Grosshans et al., 2002; Chung et al., 2004). Similarly, increased AMPAR responses after reelin application may result from enhanced single-channel activity through 
phosphorylation of specific Ser/Thr or tyrosine residues (Barria et al., 1997; Banke et al., 2000; Lee et al., 2000; Hayashi and Huganir, 2004) or from increased AMPAR trafficking to the synaptic sites (Shi et al., 1999; Hayashi et al., 2000; Man et al., 2003). We therefore first examined the phosphorylation levels of two serine residues of AMPAR subunit GluR1, Ser831 and Ser845; both can be increased during certain forms of synaptic plasticity (Barria et al., 1997; Lee et al., 2000). We found no significant changes of p-Ser831, p-Ser845, or total GluR1 levels in CA1 tissues after $1 \mathrm{~h}$ of reelin $(20 \mathrm{nM})$ application compared with those receiving $1 \mathrm{~h}$ of mock application (Fig. $5 A$ ) ( $n=4$; data not shown). Given that reelin application leads to Src activation and that tyrosine phosphorylation of AMPAR subunits by Src has been recently established as another major mechanism for regulated AMPAR endocytosis and receptor function during plasticity (Ahmadian et al., 2004; Hayashi and Huganir, 2004), we next examined levels of tyrosine phosphorylation of GluR1 and GluR2/3 subunits by immunoprecipitating CA1 tissue with GluR1 and GluR2/3 antibodies followed by immunoblotting with pY, GluR1, and GluR2/3 antibodies. No significant changes of tyrosine phosphorylation of either GluR1 or GluR2/3 subunits were observed. In addition, reblotting of the immunoprecipitated proteins with GluR1 and GluR2/3 antibodies confirmed that the same amount of total proteins was immunoprecipitated (Fig. $5 B)(n=3$; quantification not shown). These results suggest that increased AMPAR response is not attributable to enhanced AMPAR channel activity resulting from increased receptor phosphorylation.

We hypothesized that reelin enhances AMPAR responses because of increased surface insertion of AMPA receptors. We tested this hypothesis by examining levels of surface GluR1 and GluR2/3 at synaptic sites. Total surface proteins were biotinylated. After subcellular fractionation, the proteins contained in the synaptic membrane fraction were isolated with avidin beads and subjected to Western blot analysis. The total crude synaptosome proteins were blotted with the same antibodies to serve as controls. We found that both surface GluR1 and GluR2/3 levels were significantly increased after reelin treatment (Fig. 5C,D) (sGluR1: mock treated, $100 \pm 6.7 \%$; reelin treated, $138.2 \pm 8.3 \%$; $n=4 ; p<0.05$; sGluR2/3: mock treated, $100 \pm 5.1 \%$; reelin treated, $157.5 \pm 6.3 \% ; n=4 ; p<0.01$; two-way ANOVA test). In comparison, no significant change of surface levels of NR1, NR2A, or NR2B was observed. The total amounts of all of these glutamate receptor subunits in the crude synaptosome fraction did not change significantly (Fig. $5 C)(n=5$; quantification not shown). Therefore, unlike the effects of reelin on NMDARs, increased AMPAR currents after reelin application were associated with increased synaptic AMPAR contents.

We next confirmed our biochemical observation that reelin increased synaptic AMPAR numbers by electrophysiological
C
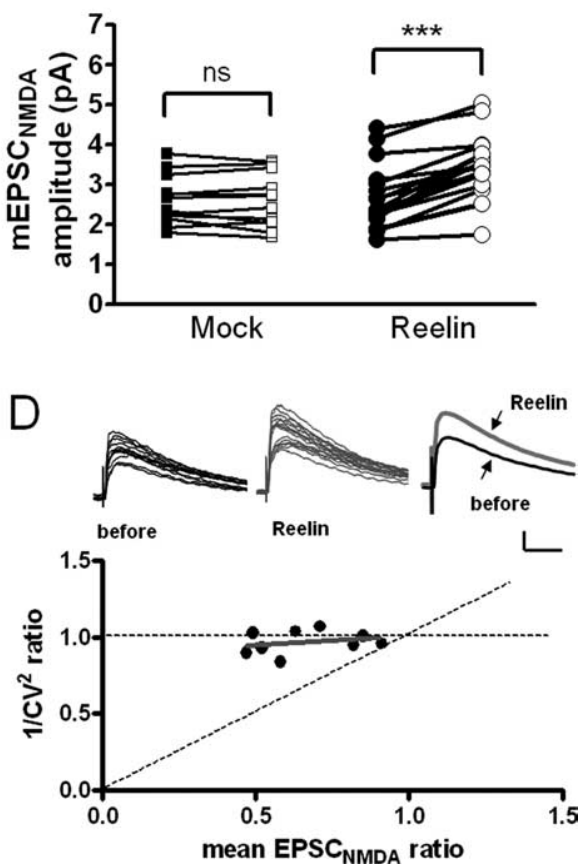

Figure 3. Reelin enhances NMDAR currents through postsynaptic mechanisms. $\boldsymbol{A}, \boldsymbol{B}$, Illustration of measurement of EPSC ${ }_{\mathrm{NMDA}}$ mithout effect [closed square, before mock; open square, after mock; not significant (ns), $p>0.05 ; n=13 ;$ paired of 15 consecutive EPSC $C_{\text {A A }}$ responses before (left) and at 30-35 min after (middle) reelin application are plotted. The averages of these traces are shown in the right. mini, mEPSC. Calibration: $\boldsymbol{A}, 10 \mathrm{pA}, 100 \mathrm{~ms} ; \boldsymbol{D}, 20 \mathrm{pA}, 50 \mathrm{~ms}$.

studies using acute hippocampal slices. Application of reelin $(20$ $\mathrm{nM}$ ) for $1 \mathrm{~h}$ increased amplitude of AMPAR-mediated mEPSCs under voltage-clamped $(-65 \mathrm{mV})$ conditions (Fig. 6A). Approximately 2000 mEPSCs from mock- or reelin-treated slices obtained from seven experiments were pooled, and the cumulative distributions of mEPSC amplitude were compared. Reelin treatment significantly increased mEPSC amplitude (Fig. $6 B)(p<$ 0.02 ; Kolmogorov-Smirnov test) without altering mEPSC frequency distribution (Fig. $6 C)(p>0.05$; Kolmogorov-Smirnov test). To estimate postsynaptic AMPAR numbers and singlechannel conductance, we conducted peak-scaled nonstationary fluctuation analysis of mEPSCs (Traynelis et al., 1993; Benke et al., 1998). The results from one representative experiment were shown in Figure 6, $D$ and E. Eighty-six consecutive mEPSCs before reelin application and 107 consecutive mEPSCs at $1 \mathrm{~h}$ after reelin application were superimposed. It was observed that the mean amplitude of mEPSCs was increased by $~ 50 \%$, whereas the kinetics of mEPSC remained unchanged. After peak scaling the mean EPSC to each mEPSC, the mean EPSC amplitude was plotted against calculated variance of the difference currents, and the curves were fitted as described in Materials and Methods. From this experiment, it was estimated that averaged weightedmean single-channel conductance was $13.0 \pm 1.4 \mathrm{pS}$ before reelin application and $13.4 \pm 1.7 \mathrm{pS}$ after reelin application; the number of AMPARs that open at the peak of mean current was $21.6 \pm 2.8$ before reelin application and $32.3 \pm 2.3$ after reelin application 

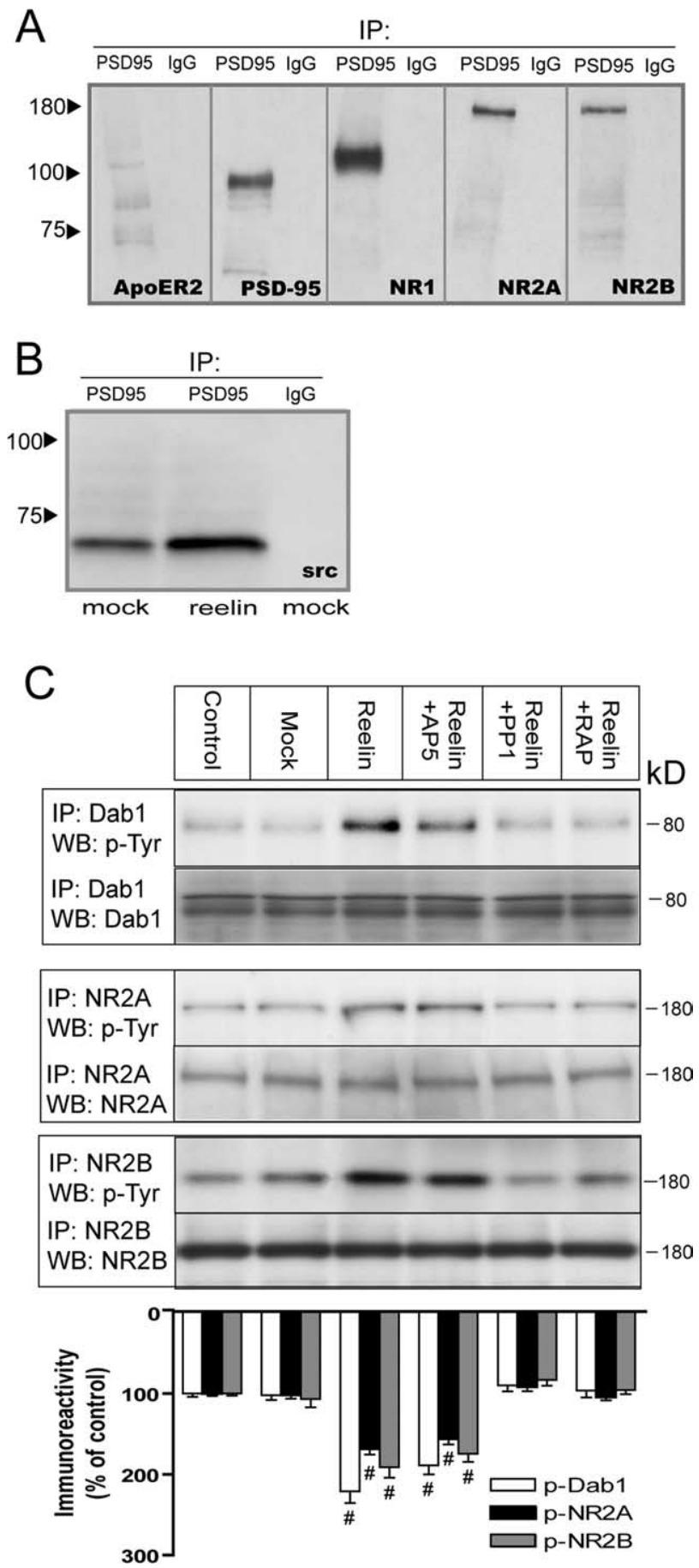

Figure 4. Reelin receptor and Src-dependent increase of tyrosine phosphorylation of NMDAR subunits NR2A and NR2B after reelin application. $A$, Physical association of the reelin signaling components. ApoER2 and NMDAR subunits are associated with the postsynaptic scaffolding protein PSD-95. CA1 lysates were immunoprecipitated with either PSD-95 antibody or normal mouse IgG and immunoblotted with antibodies as labeled on the blots. B, Src immunoreactivity was detected in the proteins that coimmunoprecipitate with PSD-95. Note a marked increase of Src association with PSD-95 in slices that were treated with reelin. C, Top, Representative blots showing levels of phosphotyrosine in immunoprecipitated proteins and amount of total immunoprecipitated proteins after treatment with reelin or in combination with PP1 or GST-RAP. Bottom, Quantitative analysis of immunoreactivity on the levels of phosphotyrosine. Reelin application significantly increased Dab1 tyrosine phosphorylation $\left(n=5\right.$; ${ }^{\#} p<0.001$; one-way ANOVA), which is completely blocked by PP1 or GST-RAP ( $n=5 ; p>0.05$ for both, compared with mock) but not by D-AP5. Reelin treatment significantly increased tyrosine phosphorylation of both NR2A $\left(n=5 ;{ }^{\#}<<0.001\right)$ and NR2B $\left(n=5 ;{ }^{\#} p<0.001\right)$. Both PP1 and GST-RAP blocked reelin-induced tyrosine phosphorylation of NR2A and NR2B. WB, Western blot. Error bars indicate SEM.
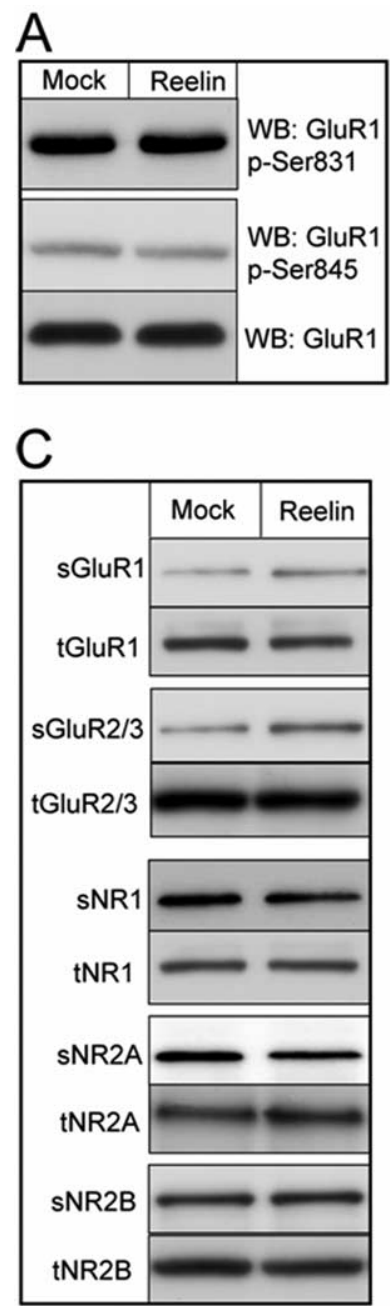

\begin{tabular}{l} 
B \\
\begin{tabular}{|l|l|l|}
\hline & Mock & Reelin \\
\hline $\begin{array}{l}\text { IP: GluR1 } \\
\text { WB: } p \text {-Tyr }\end{array}$ & \\
\hline $\begin{array}{l}\text { IP: GluR1 } \\
\text { WB: GluR1 }\end{array}$ & \\
\hline & \\
\hline $\begin{array}{l}\text { IP:GluR2/3 } \\
\text { WB: } p-T y r\end{array}$ & \\
\hline $\begin{array}{l}\text { IP:GluR2/3 } \\
\text { WB: GluR2/3 }\end{array}$ & \\
\hline
\end{tabular} \\
\hline
\end{tabular}

Figure 5. Reelin application increases surface expression of AMPAR subunits but not NMDAR subunits at synaptic sites. $A$, Representative Western blots from four experiments showing lack of changes of levels of $\mathrm{p}$-Ser831 and p-Ser845 in CA1 lysates after $20 \mathrm{~nm}$ reelin application for $1 \mathrm{~h}$ compared with those from mock application. $\boldsymbol{B}$, Compared with mock, reelin application did not change tyrosine phosphorylation of either GluR1 or GluR2/3. Reblotting of immunoprecipitated proteins with GluR1 and GluR2/3 antibodies showed that the same amount of proteins was immunoprecipitated. The blots were selected from four independent tests. $C$, Representative blots showing reelin and mock application on the levels of total proteins in crude synaptosomes and the levels of surface expression of AMPAR subunits GluR1 and GluR2/3 and NMDAR subunits NR1, NR2A, and NR2B in proteins derived from synaptic membranes. D, Quantification of levels of surface proteins in synaptic membranes. Reelin application significantly increased levels of surface expression of GluR1 and GluR2/3 $\left(n=4 ;{ }^{*} p<0.05 ;{ }^{* *} p<0.01\right.$; two-way ANOVA with post hoc Student-Newman-Keuls tests) without changing NR1, NR2A, and NR2B levels. WB, Western blot; tGluR1, total GluR1; sNR1, surface NR1; tNR1, total NR1. Error bars indicate SEM.

for $1 \mathrm{~h}$ (Fig. $6 \mathrm{E}$ ). These results were repeated in eight experiments from eight slices, and it was observed that AMPAR numbers were consistently increased after reelin ( $20 \mathrm{nM}$ ) application for $1 \mathrm{~h}$ (Fig. $6 F$ ) (averaged AMPAR numbers opened during the peak of the mEPSC: before reelin, $30.5 \pm 3.1$; after reelin, $41.2 \pm 3.3 ; n=8$; $p<0.01$; paired $t$ test).

\section{Differential coupling of reelin signaling with NMDAR and AMPARs}

To further explore molecular mechanisms of reelin signaling leading to enhanced NMDAR and AMPAR function, we examined reelin effects on NMDAR- and AMPAR-mediated wholecell currents in the presence of bath-applied GST-RAP, a molec- 
ular chaperone for LDLR family members that has been shown to block reelin binding to these receptors (Herz et al., 1991; Chen et al., 2005; Sinagra et al., 2005), or $\mathrm{PP} 1$, an Src family protein tyrosine kinase inhibitor (Hanke et al., 1996). Either 20 $\mu \mathrm{M}$ GST-RAP or $1 \mu \mathrm{M}$ PP1 completely abolished reelin-induced enhancement of NMDAR whole-cell currents. In comparison, bath application of $10 \mu \mathrm{M}$ PP3, an inactive structural analog of PP1, did not change the $\mathrm{EPSC}_{\mathrm{NMDA}}$ responses after reelin application (Fig. 7A). Surprisingly, only $20 \mu \mathrm{M}$ GST-RAP abolished reelininduced increases of AMPAR response; PP1 was without effect (Fig. 7B). This suggests that reelin-induced synaptic AMPAR insertion was independent of Src activity. We hypothesized that a candidate mechanism might be PI3K-dependent insertion of AMPARs, based on the contribution of PI3K activity for certain forms of synaptic plasticity (Sanna et al., 2002; Man et al., 2003) and the fact that reelin application results in PI3K activation that is independent of Src activity (Beffert et al., 2002). Application of the PI3K-specific inhibitor wortmannin $(100 \mathrm{nM})$ for $30 \mathrm{~min}$ before reelin application completely abolished reelin enhancement of EPSC $_{\text {AMPA }}$ (Fig. $7 B)$.

To overcome the variability across experiments and rule out the potential effects of tested drugs on network activity that might affect cellular responses to reelin, we simultaneously voltage clamped two adjacent CA1 pyramidal neurons at +40 $\mathrm{mV}$ (in the presence of $20 \mu \mathrm{m}$ bicuculline and $10 \mu \mathrm{M}$ CNQX) and examined reelin effects on the synaptically evoked EPSC $_{\text {NMDA }}$. GST-RAP, PP1, or PP3 was included in one of the two recording electrodes. In the control electrode with $0.05 \%$ DMSO, reelin caused an increase of EPSC $_{\mathrm{NMDA}}$ at $30 \mathrm{~min}$ (Fig. 7C) (135.3 \pm $10.6 \%$ of baseline; $n=8$ cells from 6 slices). When PP1 was included in the recording electrode, no enhancement of EPSC $_{\mathrm{NMDA}}$ was seen $(104.6 \pm 8.7 \%$ of baseline; $n=9$ cells from 6 slices; compared with the baseline, $p>0.05$ ). In contrast, inclusion of GST-RAP or PP3 had no effect on reelin enhancement of $\mathrm{EPSC}_{\mathrm{NMDA}}$ (Fig. 7C) (GST group, $132.7 \pm 8.4 \%$; GST-RAP, $126.7 \pm 6.9 \%$; PP3, $127.5 \pm 5.9 \%$; DMSO control for PP3, $128.8 \pm 7.3 \%$; data not shown; $n=5-7$ cells from 7 slices; $p>$ 0.05). In a separate set of experiments, two CA1 neurons were simultaneously voltage clamped at $-65 \mathrm{mV}$ to examine reelin effects on AMPAR-mediated synaptic responses. Either wortmannin or another structurally distinct PI3K inhibitor, LY294002 $(50 \mu \mathrm{M})$, was included in one of the recording electrodes, whereas the paired recording electrode contained $0.05 \%$ DMSO to serve as control. It is observed that either wortmannin or LY294002 completely blocked reelin-induced enhancement of synaptic AMPAR currents (Fig. 7D) ( $n=6-8$ cells from 8 slices). Collectively, these results show that reelin potentiation of NMDAR responses is through transmembrane signaling of reelin receptors that activates Src. In contrast, the increased insertion of synaptic AMPARs is not dependent on Src but requires the activity of PI3K.
D
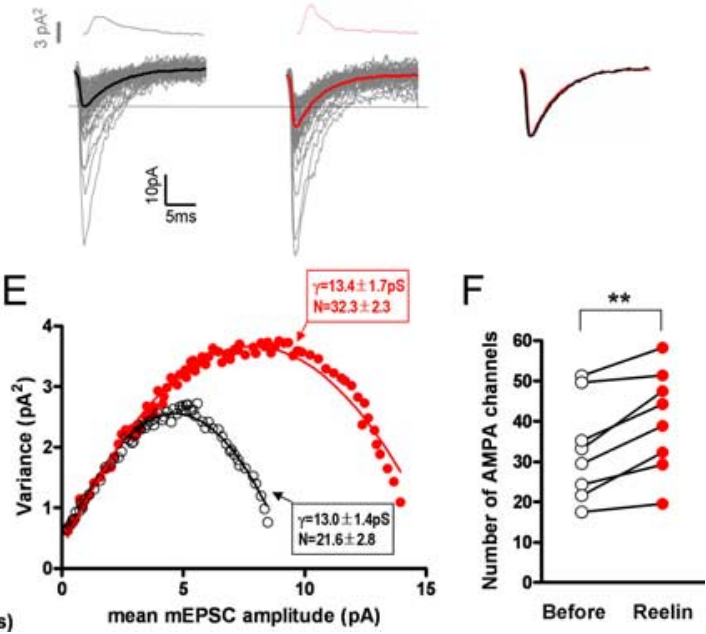

Figure 6. Increased synaptic targeting of AMPARs accounts for enhanced AMPAR currents after reelin application. $\boldsymbol{A}$, Reprecomparison, $\gamma$ remains unchanged. The mean $\mathrm{mEPSC} s$ and variances were calculated from $165 \mathrm{mEPSC}$ before reelin application and $182 \mathrm{mEPSCs}$ after reelin application. $\boldsymbol{F}$, Pooled data on the number of AMPAR channels that open during the peak of mEPSC obtained in eight experiments. Reelin application significantly increases the number of AMPARs (** $p<0.01$; paired $t$ test).

\section{Prolonged reelin treatment increases surface expression of AMPAR subunit GluR1 in cultured hippocampal neurons}

To investigate whether functional coupling of reelin signaling to enhanced glutamatergic function is of broader physiological significance, we asked whether it also functions in cultured hippocampal neurons. Embryonic hippocampal neurons under culture conditions similar to ours express all of the reelin signaling components (Beffert et al., 2002, 2005; Niu et al., 2004; Sinagra et al., 2005) (S. Qiu and E. J. Weeber, unpublished observations). We treated cultured hippocampal neurons at $14 \mathrm{~d}$ in culture with $20 \mathrm{nM}$ reelin for $12 \mathrm{~h}$ and examined the newly inserted GluR1 clusters using an N-terminal antibody under nonpermeabilized conditions (see Materials and Methods). We found that reelin treatment significantly increased GluR1 clusters located on primary dendrites (Fig. 8) (average number of GluR clusters per 100 $\mu \mathrm{m}$ dendritic segment: control, $24.2 \pm 3.3$; reelin treated, $46.5 \pm$ $2.4 ; n=11 ; p<0.01$; one-way ANOVA). Reelin effect was completely blocked by 30 min preincubation and coapplication with $20 \mu \mathrm{M}$ GST-RAP $(26.2 \pm 3.2 ; p>0.05$, compared with control group; one-way ANOVA) or $100 \mathrm{~nm}$ wortmannin $(27.3 \pm 2.2$; $p>0.05$, compared with control group; one-way ANOVA) but was not changed by $10 \mu \mathrm{M}$ PP1 or $100 \mu \mathrm{M}$ D-AP5. When applied alone for $12 \mathrm{~h}$, none of the drugs, including GST-RAP, D-AP5, PP1, and wortmannin, altered the number of GluR1 clusters. Thus, these results suggest that PI3K activation as a result of reelin signaling enhances AMPAR function by increasing receptor surface insertion, which is in agreement with our results obtained using acute hippocampal slice preparations. 
A

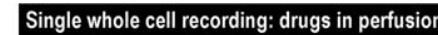

- Reelin - Reelin+GST-RAP
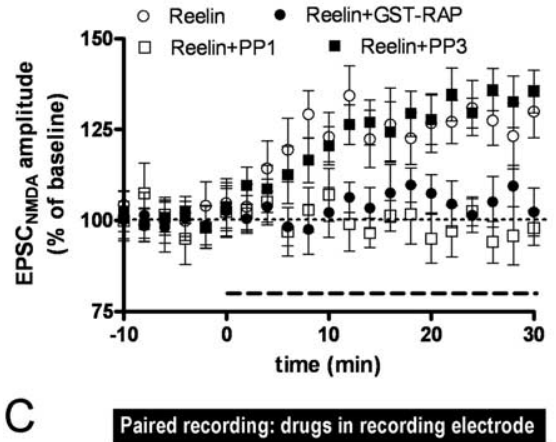

- DMSO - PP3 • PP1

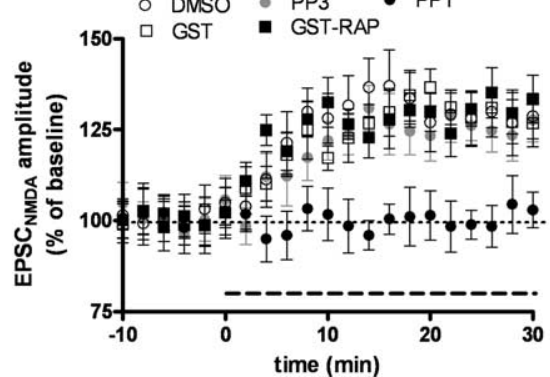

B
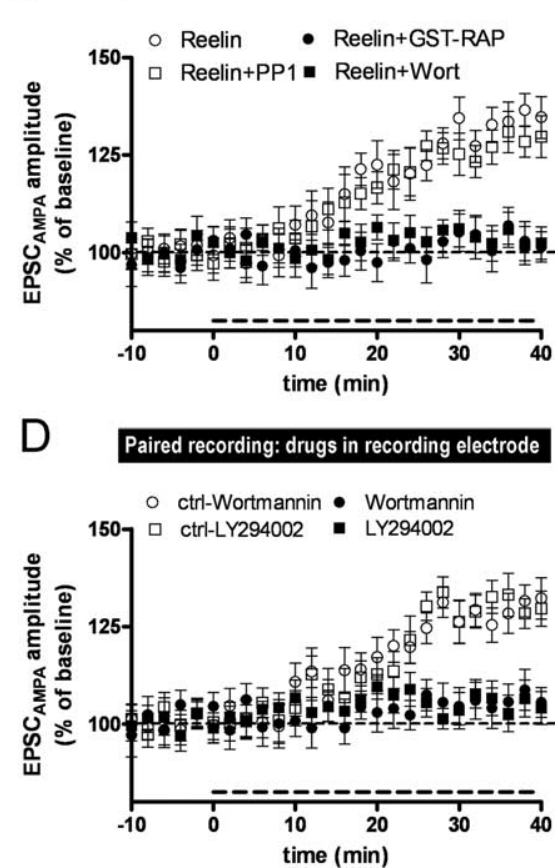

Figure 7. Distinct postsynaptic mechanisms couple reelin signaling with enhanced NMDAR and AMPAR currents. $A$, Reelin application (indicated by the horizontal dashed line) increased NMDAR whole-cell currents $(130.3 \pm 7.4 \%$ of baseline at $30 \mathrm{~min}$; $n=6 ; p<0.05)$, an effect that was not seen when slices were preapplied for 30 min with either PP1 (10 $\mu \mathrm{m} ; n=6 ; p>0.05$; compared with baseline and 30 min values) or GST-RAP $(n=6 ; p>0.05)$. Preincubation slices with $10 \mu \mathrm{M}$ PP3 did not change reelin effects on $E P C_{N M D A} \cdot \boldsymbol{B}$, Reelin enhancement of PSSC $_{\mathrm{AMPA}}$ was blocked by preincubating slices with GST-RAP or PI3K inhibitor wortmannin (Wort; $100 \mathrm{~nm}$ ). Src inhibitor PP1 was without effect. C, Simultaneous recording from two adjacent CA1 neurons showed that including PP1, but not GST-RAP or PP3, in the recording electrode abolished reelin potentiation on EPSC $_{\text {NMDA }}$ (comparison between baseline and 30 min values; GST, DMSO, GST-RAP, and PP3: $n=5-8, p<0.01 ; \mathrm{PP1}: n=9, p>$ 0.05). D, Including either wortmannin (100 nM) or LY294002 $(50 \mu \mathrm{m})$, but not the dissolvent [0.05\% DMSO for the control (ctrl)-Wortmannin and ctrl-LY294002 groups], in the recording electrode completely abolished reelin enhancement of synaptic EPSC $_{\text {AMPA }}$. Error bars indicate SEM.

\section{Discussion}

In this study, we investigated the functional consequences of reelin signaling in the adult hippocampus. One important finding is that reelin signaling through postsynaptic mechanisms differentially regulates NMDAR and AMPAR function, leading to enhanced synaptic transmission and plasticity. It has been well established that reelin-induced signaling through apoER2 and VLDLR, the intracellular adaptor protein Dab1, and Src family protein tyrosine kinases is critical in embryonic brain development (D’Arcangelo et al., 1995; Goffinet, 1995; Howell et al., 1997, 1999a; Bock and Herz, 2003; Kuo et al., 2005). Recent studies have shown that this system also interacts intracellularly with an array of signaling pathways involving cdk5 (cyclin-dependent kinase 5), JIP (c-Jun N-terminal kinase-interacting protein), PI3K, PKB, GSK-3 $\beta$ (glycogen synthase kinase- $3 \beta$ ), Lis-1 (lissencephaly 1), and CrK family adaptor proteins (Beffert et al., 2002; Arnaud et al., 2003; Assadi et al., 2003; Bock and Herz, 2003; Ballif et al., 2004), suggesting that reelin may be involved in multiple aspects of neuronal development and physiology. Moreover, reelin-lipoprotein receptor-mediated signaling also plays an important role in neuronal maturation, synaptic plasticity, and memory formation (Nimpf and Schneider, 2000; Weeber et al., 2002; Beffert et al., 2005; D'Arcangelo, 2005). Not surprisingly, aberrant reelin levels have been implicated in the pathogenesis of a number of neurodegenerative and psychiatric disorders, such as Alzheimer's disease (Botella-Lopez et al., 2006), schizophrenia, lissencephaly, bipolar disease, and autism (for review, see Qiu et al., 2006).

Although reelin is abundantly expressed in the postnatal brain (Pesold et al., 1998; Roberts et al., 2005; RamosMoreno et al., 2006), its functional role remains enigmatic. We have shown previously that reelin enhances tetanusinduced LTP in CA1 by activating apoER2 and VLDLR and hypothesized a potential role of reelin signaling in modulating synaptic transmission and plasticity (Weeber et al., 2002). Indeed, one of the reelin receptors, apoER2, may be well suited to modulate glutamatergic responses, for several reasons. First, apoER2 and NMDAR are physically associated, coimmunoprecipitate in heterologous expression cell lines, and colocalize in CA1 postsynaptic densities (Beffert et al., 2005; Hoe et al., 2006). These observations were further confirmed in CA1 tissues by this study. Second, reelin-induced enhancement of LTP and phosphorylation of NMDAR subunits are dependent on the intracellular domain of apoER2 encoded by exon 19 , which is also crucial for maintaining normal associative and spatial learning (Beffert et al., 2005). Third, like NMDARs, apoER2 also binds to PDZ (PSD-95/Discs large/Zona occludens-1) domains of PSD-95 (Hoe et al., 2006) and therefore may recruit Src through postsynaptic scaffolding proteins and result in NMDAR tyrosine phosphorylation. Our finding (Fig. 4) that Src is associated with apoER2 through PSD-95 and is dynamically recruited to PSD-95 after reelin application supports this hypothesis.

We further investigated mechanisms for reelin-induced enhancement of synaptic strength. Reelin increases magnitude of pairing-induced LTP and enhances both NMDAR- and AMPARmediated whole-cell currents (Figs. 1,2). Analysis of paired-pulse ratios of fEPSP, synaptic EPSC ${ }_{\mathrm{AMPA}}$, and mEPSC $_{\mathrm{NMDA}}$ amplitudes confirms a postsynaptic locus of reelin action, which is in agreement with our biochemical data showing increased tyrosine phosphorylation of NR2A and NR2B. Because mEPSC $_{\mathrm{NMDA}}$ was studied in $\mathrm{Mg}^{2+}$-free conditions, which could enhance release probability to the extent that prevents additional changes of presynaptic release, we performed variance-mean analysis of synaptic $\mathrm{EPSC}_{\mathrm{NMDA}}$. Although reelin increased synaptic $\mathrm{EPSC}_{\mathrm{NMDA}}$ amplitude, it did not increase its variance. These results confirmed a postsynaptic locus of reelin signaling in CA1.

In light of our findings that reelin increased synaptic EP$\mathrm{SC}_{\mathrm{AMPA}}$ under voltage-clamped conditions, we sought to determine the molecular mechanisms leading to enhanced AMPAR response. Activity-dependent AMPAR phosphorylation at both serine (Ser831 and Ser845) and tyrosine residues accounts for increased receptor unitary conductance, synaptic trafficking, and long-lasting changes of synaptic strength (Barria et al., 1997; Benke et al., 1998; Lee et al., 2000; Hayashi and Huganir, 2004). We found that reelin signaling did not change phosphorylation levels of Ser831, Ser845, or tyrosine residues of AMPAR subunits, 


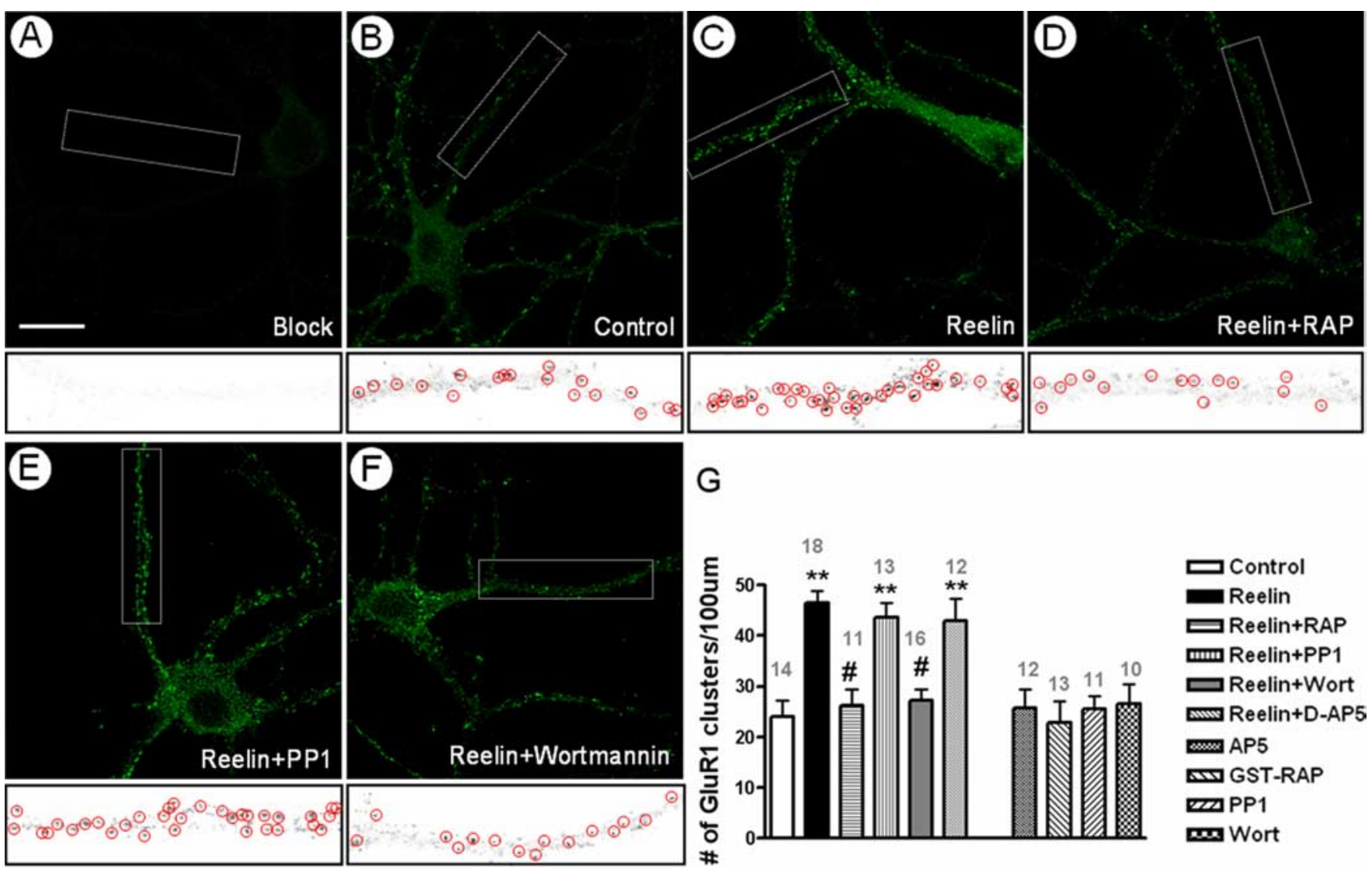

Figure 8. Reelin enhances surface clustering of AMPARs in cultured hippocampal neurons. $A$, No GluR1 signal was detected right after surface GluR1 was blocked with an N-terminal antibody. $\boldsymbol{B}-\boldsymbol{F}$, Newly inserted GluR1 clusters were detected after an additional $12 \mathrm{~h}$ culture $(\boldsymbol{B})$ or in the presence of $20 \mathrm{~nm}$ reelin $(\boldsymbol{C}$, reelin plus GST-RAP (20 $\mu \mathrm{m} ; \boldsymbol{D})$, reelin plus PP1 (10 $\mu \mathrm{m} ; \boldsymbol{E})$, or reelin plus wortmannin $(100 \mathrm{~nm} ; \boldsymbol{F})$. The boxed region in each panel was enlarged, reverse displayed, and placed under the corresponding graph for enlarged views. The punctate GluR1 clustering was encircled. $G$, Quantitative analysis of surface GluR1 clustering after different treatments. Data were pooled from four different cultures, and the number of neurons analyzed was marked on top of each group. Reelin significantly increased surface clustering of GluR1 ${ }^{* *} p<0.01$, compared with that of control group; one-way ANOVA test). Coapplication of GST-RAP or wortmannin (Wort) with reelin significantly lowered the number of surface GluR1 clusters to levels close to the control level (compared with reelin alone, ${ }^{\#} p<0.01$; one-way ANOVA). Coapplication of PP1 or D-AP5 with reelin did not change reelin effects on surface GluR1 clustering (compared with reelin, $p>0.05$ for both groups). Error bars indicate SEM.

suggesting that Src specifically phosphorylates NMDAR in response to reelin signaling. Although Src family PTKs are also known to phosphorylate AMPAR receptor subunits (Hayashi and Huganir, 2004), it is not clear from this study what confers their preference for NMDARs. Alternatively, enhanced synaptic strength can be achieved through increased synaptic targeting of AMPAR subunits (Shi et al., 1999; Hayashi et al., 2000; Man et al., 2003). We found a significant increase in surface expression of AMPAR subunits but not NMDAR subunits at the synaptic sites after reelin application. This is in agreement with our estimation of the number of AMPARs that open during the peak of mEPSC using nonstationary noise-analysis techniques.

We have further shown that the same molecular signaling cascade involving reelin, its lipoprotein receptors, and Src is also operating in adult brain to enhance glutamatergic function. Reelin application resulted in increased tyrosine phosphorylation of both NR2A and NR2B without changing their surface levels at synaptic sites. Additionally, the increased tyrosine phosphorylation was blocked by the LDLR family member antagonist GSTRAP (Herz et al., 1991) and Src inhibitor PP1 (Hanke et al., 1996). Furthermore, dialysis of the postsynaptic neuron with PP1, but not GST-RAP or PP3, abolished reelin enhancement of EPSC $_{\mathrm{NMDA}}$. These results suggest that increased $\mathrm{EPSC}_{\mathrm{NMDA}}$ and tyrosine phosphorylation of NMDAR are results of transmembrane signaling involving extracellular reelin receptors and intra- cellular Src kinase. Consistently, we also found that all major components, including apoER2, Src, and NMDAR subunits, that are involved in reelin signaling are also physically associated with PSD-95 protein. Moreover, reelin signaling recruits more Src to associate with PSD-95, which could be the molecular basis for increased tyrosine phosphorylation of NMDARs. These results agree with a recent biochemical study on the interaction of apoER2 with NMDARs (Hoe et al., 2006), in which it has been shown that apoER2 interacts directly with NR1 extracellular domain and with the PDZ1 domain of PSD-95 intracellularly. Collectively, our results have unequivocally shown that increased tyrosine phosphorylation by Src accounts for the increased EPSC $_{\text {NMDA }}$. Because tyrosine phosphorylation increases NMDAR currents and leads to LTP (Wang and Salter, 1994; Yu et al., 1997; Lu et al., 1998), the increased NMDAR activity may be the physiological basis for reelin-enhanced synaptic plasticity, such as elevated magnitude of pairing-induced LTP.

Another novel aspect of this study is that we have revealed a functional coupling of reelin signaling with enhanced AMPAR function that is achieved through a PI3K-dependent insertion of AMPARs at synaptic sites. We have found previously that a short application (10 min) of reelin (5 nM) did not change field potential responses but significantly enhanced tetanus-induced LTP in CA1 (Weeber et al., 2002). In comparison, current study revealed that application of reelin at higher concentration or for pro- 


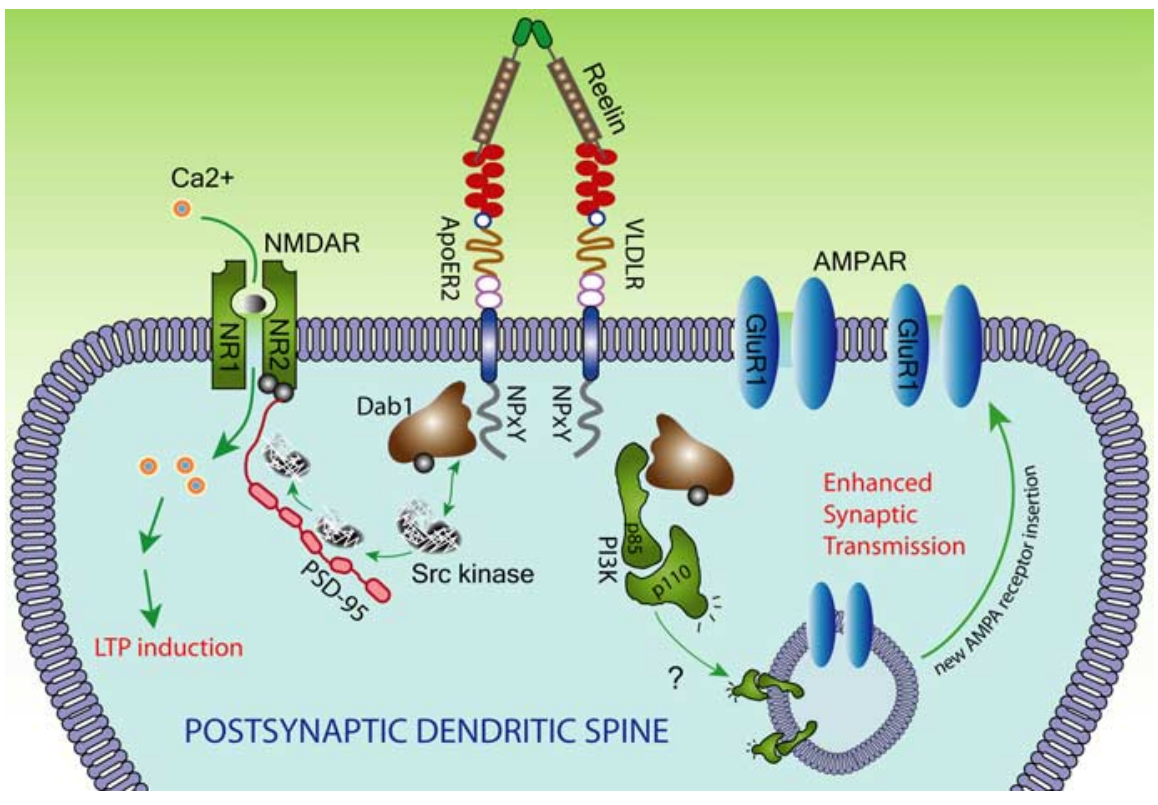

Figure 9. Potential mechanisms by which reelin signaling regulates synaptic transmission and plasticity in the postnatal hippocampus. Activation of apoER2/VLDLR by reelin leads to tyrosine phosphorylation of Dab1, activation of Src, and subsequent increased association of Src with the postsynaptic scaffolding protein PSD-95. Tyrosine phosphorylation of the NR2 subunits, which is physically associated with PSD-95, is increased. This translates into increased synaptic NMDA receptor currents, larger $\mathrm{Ca}^{2+}$ influx, and elevated LTP magnitude. However, reelin signaling leads to activation of PI3 kinase (Beffert et al., 2002), which drives the intracellular pool of AMPARs for synaptic delivery through less characterized mechanisms (Man et al., 2003), favoring synaptic transmission at resting membrane potentials.

longed duration leads to increased synaptic responses mediated by AMPARs through PI3K-dependent mechanisms. PI3K converts phosphatidylinositol 4,5 bisphosphate into phosphatidylinositol 3,4,5-trisphosphate and induces a broad array of cellular processes in neurons. For example, PI3K is compartmentalized in excitatory synapses of hippocampal neurons, and its downstream signaling components involving Akt and mammalian target of rapamycin are required for developing normal dendritic structure (Man et al., 2003; Jaworski et al., 2005). It has been shown that both induction and expression of LTP requires PI3K activity (Kelly and Lynch, 2000; Sanna et al., 2002; Opazo et al., 2003). $\mathrm{PI} 3 \mathrm{~K}$ is also physically associated with AMPARs and functionally coupled with AMPAR subunit trafficking during certain forms of plasticity, such as potentiation of mEPSC in response to activation of L-type calcium channels (Baxter and Wyllie, 2006) or synaptic NMDARs (Man et al., 2003). Multiple cellular processes can lead to activation of PI3K, such as activation of Src (Krymskaya et al., 2005), G-protein-coupled receptors (Shah et al., 2006), and $\mathrm{Ca}^{2+}$ - calmodulin complex after NMDAR activation (Joyal et al., 1997; Man et al., 2003). It has been shown that reelin signaling leads to PI3K-dependent activation of Akt in cultured embryonic neurons, and activation of PI3K by reelin does not require Src activity but requires direct interaction of the phosphotyrosine-binding domain of Dab1 with the phospholipid substrates of PI3K (Howell et al., 1999b; Beffert et al., 2002). Although the exact mechanisms leading to increased AMPAR insertion and long-lasting changes of synaptic strength after reelin signaling and PI3K activation remain to be elucidated, a causative connection of reelin, PI3K activity, and increased AMPAR insertion has been established by this study.

In summary, our data have revealed a previously unappreciated role for reelin signaling in adult hippocampal synaptic function. We have outlined a complete signaling pathway that involves reelin acting on its receptors, leading to enhanced synaptic transmission and plasticity (Fig. 9). The postsynaptic locus of reelin action has been confirmed, and a causative connection between increased Src activity and NMDAR has been established for the first time by this study. Additionally, we have shown that enhanced reelin signaling strengthens synaptic transmission by facilitating AMPA receptor subunit surface insertion through PI3K-dependent mechanisms. These results shed new light on the postnatal function of reelin- and lipoprotein receptor-mediated signaling in synaptic transmission, plasticity, and potentially memory function, by showing that converging signaling processes mediated by CNS lipoprotein receptors, their ligand reelin, and intracellular signaling components act in concert to modulate postnatal brain function.

\section{References}

Abraham H, Meyer G (2003) Reelin-expressing neurons in the postnatal and adult human hippocampal formation. Hippocampus 13:715-727.

Ahmadian G, Ju W, Liu L, Wyszynski M, Lee SH, Dunah AW, Taghibiglou C, Wang Y, Lu J, Wong TP, Sheng M, Wang YT (2004) Tyrosine phosphorylation of GluR2 is required for insulin-stimulated AMPA receptor endocytosis and LTD. EMBO J 23:1040-1050.

Alcantara S, Ruiz M, D’Arcangelo G, Ezan F, de Lecea L, Curran T, Sotelo C, Soriano E (1998) Regional and cellular patterns of reelin mRNA expression in the forebrain of the developing and adult mouse. J Neurosci 18:7779-7799.

Arnaud L, Ballif BA, Cooper JA (2003) Regulation of protein tyrosine kinase signaling by substrate degradation during brain development. Mol Cell Biol 23:9293-9302.

Assadi AH, Zhang G, Beffert U, McNeil RS, Renfro AL, Niu S, Quattrocchi CC, Antalffy BA, Sheldon M, Armstrong DD, Wynshaw-Boris A, Herz J, D'Arcangelo G, Clark GD (2003) Interaction of reelin signaling and Lis1 in brain development. Nat Genet 35:270-276.

Ballif BA, Arnaud L, Arthur WT, Guris D, Imamoto A, Cooper JA (2004) Activation of a Dab1/CrkL/C3G/Rapl pathway in Reelin-stimulated neurons. Curr Biol 14:606-610.

Banke TG, Bowie D, Lee H, Huganir RL, Schousboe A, Traynelis SF (2000) Control of GluR1 AMPA receptor function by cAMP-dependent protein kinase. J Neurosci 20:89-102.

Barria A, Muller D, Derkach V, Griffith LC, Soderling TR (1997) Regulatory phosphorylation of AMPA-type glutamate receptors by CaM-KII during long-term potentiation. Science 276:2042-2045.

Baxter AW, Wyllie DJ (2006) Phosphatidylinositol 3 kinase activation and AMPA receptor subunit trafficking underlie the potentiation of miniature EPSC amplitudes triggered by the activation of L-type calcium channels. J Neurosci 26:5456-5469.

Beffert U, Morfini G, Bock HH, Reyna H, Brady ST, Herz J (2002) Reelinmediated signaling locally regulates protein kinase B/Akt and glycogen synthase kinase 3beta. J Biol Chem 277:49958-49964.

Beffert U, Weeber EJ, Durudas A, Qiu S, Masiulis I, Sweatt JD, Li WP, Adelmann G, Frotscher M, Hammer RE, Herz J (2005) Modulation of synaptic plasticity and memory by Reelin involves differential splicing of the lipoprotein receptor Apoer2. Neuron 47:567-579.

Benhayon D, Magdaleno S, Curran T (2003) Binding of purified Reelin to ApoER2 and VLDLR mediates tyrosine phosphorylation of Disabled-1. Brain Res Mol Brain Res 112:33-45.

Benke TA, Luthi A, Isaac JT, Collingridge GL (1998) Modulation of AMPA receptor unitary conductance by synaptic activity. Nature 393:793-797. 
Bock HH, Herz J (2003) Reelin activates SRC family tyrosine kinases in neurons. Curr Biol 13:18-26.

Bolshakov VY, Siegelbaum SA (1994) Postsynaptic induction and presynaptic expression of hippocampal long-term depression. Science 264:1148-1152.

Botella-Lopez A, Burgaya F, Gavin R, Garcia-Ayllon MS, Gomez-Tortosa E, Pena-Casanova J, Urena JM, Del Rio JA, Blesa R, Soriano E, Saez-Valero J (2006) Reelin expression and glycosylation patterns are altered in Alzheimer's disease. Proc Natl Acad Sci USA 103:5573-5578.

Broutman G, Baudry M (2001) Involvement of the secretory pathway for AMPA receptors in NMDA-induced potentiation in hippocampus. J Neurosci 21:27-34.

Chen Y, Beffert U, Ertunc M, Tang TS, Kavalali ET, Bezprozvanny I, Herz J (2005) Reelin modulates NMDA receptor activity in cortical neurons. J Neurosci 25:8209-8216.

Chung HJ, Huang YH, Lau LF, Huganir RL (2004) Regulation of the NMDA receptor complex and trafficking by activity-dependent phosphorylation of the NR2B subunit PDZ ligand. J Neurosci 24:10248-10259.

D'Arcangelo G (2005) Apoer2: a reelin receptor to remember. Neuron 47:471-473.

D’Arcangelo G, Miao GG, Chen SC, Soares HD, Morgan JI, Curran T (1995) A protein related to extracellular matrix proteins deleted in the mouse mutant reeler. Nature 374:719-723.

D’Arcangelo G, Nakajima K, Miyata T, Ogawa M, Mikoshiba K, Curran T (1997) Reelin is a secreted glycoprotein recognized by the CR-50 monoclonal antibody. J Neurosci 17:23-31.

D’Arcangelo G, Homayouni R, Keshvara L, Rice DS, Sheldon M, Curran T (1999) Reelin is a ligand for lipoprotein receptors. Neuron 24:471-479.

Del Rio JA, Heimrich B, Borrell V, Forster E, Drakew A, Alcantara S, Nakajima K, Miyata T, Ogawa M, Mikoshiba K, Derer P, Frotscher M, Soriano E (1997) A role for Cajal-Retzius cells and reelin in the development of hippocampal connections. Nature 385:70-74.

Frerking M, Schmitz D, Zhou Q, Johansen J, Nicoll RA (2001) Kainate receptors depress excitatory synaptic transmission at CA3 $\rightarrow$ CA1 synapses in the hippocampus via a direct presynaptic action. J Neurosci 21:2958-2966.

Goffinet AM (1995) Developmental neurobiology. A real gene for reeler. Nature 374:675-676.

Grosshans DR, Clayton DA, Coultrap SJ, Browning MD (2002) LTP leads to rapid surface expression of NMDA but not AMPA receptors in adult rat CA1. Nat Neurosci 5:27-33.

Hanke JH, Gardner JP, Dow RL, Changelian PS, Brissette WH, Weringer EJ, Pollok BA, Connelly PA (1996) Discovery of a novel, potent, and Src family-selective tyrosine kinase inhibitor. Study of Lck- and FynTdependent $\mathrm{T}$ cell activation. J Biol Chem 271:695-701.

Hayashi T, Huganir RL (2004) Tyrosine phosphorylation and regulation of the AMPA receptor by SRC family tyrosine kinases. J Neurosci 24:6152-6160.

Hayashi Y, Shi SH, Esteban JA, Piccini A, Poncer JC, Malinow R (2000) Driving AMPA receptors into synapses by LTP and CaMKII: requirement for GluR1 and PDZ domain interaction. Science 287:2262-2267.

Herz J, Goldstein JL, Strickland DK, Ho YK, Brown MS (1991) 39-kDa protein modulates binding of ligands to low density lipoprotein receptorrelated protein/alpha 2-macroglobulin receptor. J Biol Chem 266:21232-21238.

Hiesberger T, Trommsdorff M, Howell BW, Goffinet A, Mumby MC, Cooper JA, Herz J (1999) Direct binding of Reelin to VLDL receptor and ApoE receptor 2 induces tyrosine phosphorylation of disabled-1 and modulates tau phosphorylation. Neuron 24:481-489.

Hoe HS, Pocivavsek A, Chakraborty G, Fu Z, Vicini S, Ehlers MD, Rebeck GW (2006) Apolipoprotein E receptor 2 interactions with the $N$-methyl-Daspartate receptor. J Biol Chem 281:3425-3431.

Howell BW, Hawkes R, Soriano P, Cooper JA (1997) Neuronal position in the developing brain is regulated by mouse disabled-1. Nature 389:733-737.

Howell BW, Herrick TM, Cooper JA (1999a) Reelin-induced tyrosine [corrected] phosphorylation of disabled 1 during neuronal positioning. Genes Dev 13:643-648.

Howell BW, Lanier LM, Frank R, Gertler FB, Cooper JA (1999b) The disabled 1 phosphotyrosine-binding domain binds to the internalization signals of transmembrane glycoproteins and to phospholipids. Mol Cell Biol 19:5179-5188.
Jaworski J, Spangler S, Seeburg DP, Hoogenraad CC, Sheng M (2005) Control of dendritic arborization by the phosphoinositide-3'-kinase-Aktmammalian target of rapamycin pathway. J Neurosci 25:11300-11312.

Joyal JL, Burks DJ, Pons S, Matter WF, Vlahos CJ, White MF, Sacks DB (1997) Calmodulin activates phosphatidylinositol 3-kinase. J Biol Chem 272:28183-28186.

Kelly A, Lynch MA (2000) Long-term potentiation in dentate gyrus of the rat is inhibited by the phosphoinositide 3-kinase inhibitor, wortmannin. Neuropharmacology 39:643-651.

Krymskaya VP, Goncharova EA, Ammit AJ, Lim PN, Goncharov DA, Eszterhas A, Panettieri Jr RA (2005) Src is necessary and sufficient for human airway smooth muscle cell proliferation and migration. FASEB J 19:428-430.

Kuo G, Arnaud L, Kronstad-O’Brien P, Cooper JA (2005) Absence of Fyn and Src causes a reeler-like phenotype. J Neurosci 25:8578-8586.

Lan JY, Skeberdis VA, Jover T, Zheng X, Bennett MV, Zukin RS (2001) Activation of metabotropic glutamate receptor 1 accelerates NMDA receptor trafficking. J Neurosci 21:6058-6068.

Lau LF, Huganir RL (1995) Differential tyrosine phosphorylation of $N$-methyl-D-aspartate receptor subunits. J Biol Chem 270:20036-20041.

Lee HK, Barbarosie M, Kameyama K, Bear MF, Huganir RL (2000) Regulation of distinct AMPA receptor phosphorylation sites during bidirectional synaptic plasticity. Nature 405:955-959.

Lei G, Xue S, Chery N, Liu Q, Xu J, Kwan CL, Fu YP, Lu YM, Liu M, Harder KW, Yu XM (2002) Gain control of N-methyl-D-aspartate receptor activity by receptor-like protein tyrosine phosphatase alpha. EMBO J 21:2977-2989.

Lu YM, Roder JC, Davidow J, Salter MW (1998) Src activation in the induction of long-term potentiation in CA1 hippocampal neurons. Science 279:1363-1367.

Man HY, Wang Q, Lu WY, Ju W, Ahmadian G, Liu L, D’Souza S, Wong TP, Taghibiglou C, Lu J, Becker LE, Pei L, Liu F, Wymann MP, MacDonald JF, Wang YT (2003) Activation of PI3-kinase is required for AMPA receptor insertion during LTP of mEPSCs in cultured hippocampal neurons. Neuron 38:611-624.

Nimpf J, Schneider WJ (2000) From cholesterol transport to signal transduction: low density lipoprotein receptor, very low density lipoprotein receptor, and apolipoprotein E receptor-2. Biochim Biophys Acta 1529:287-298.

Niu S, Renfro A, Quattrocchi CC, Sheldon M, D’Arcangelo G (2004) Reelin promotes hippocampal dendrite development through the VLDLR/ ApoER2-Dab1 pathway. Neuron 41:71-84.

Opazo P, Watabe AM, Grant SG, O’Dell TJ (2003) Phosphatidylinositol 3-kinase regulates the induction of long-term potentiation through extracellular signal-related kinase-independent mechanisms. J Neurosci 23:3679-3688.

Pesold C, Impagnatiello F, Pisu MG, Uzunov DP, Costa E, Guidotti A, Caruncho HJ (1998) Reelin is preferentially expressed in neurons synthesizing gamma-aminobutyric acid in cortex and hippocampus of adult rats. Proc Natl Acad Sci USA 95:3221-3226.

Qiu S, Korwek KM, Weeber EJ (2006) A fresh look at an ancient receptor family: emerging roles for low density lipoprotein receptors in synaptic plasticity and memory formation. Neurobiol Learn Mem 85:16-29.

Ramos-Moreno T, Galazo MJ, Porrero C, Martinez-Cerdeno V, Clasca F (2006) Extracellular matrix molecules and synaptic plasticity: immunomapping of intracellular and secreted Reelin in the adult rat brain. Eur J Neurosci 23:401-422.

Roberts RC, Xu L, Roche JK, Kirkpatrick B (2005) Ultrastructural localization of reelin in the cortex in post-mortem human brain. J Comp Neurol 482:294-308.

Salter MW, Kalia LV (2004) Src kinases: a hub for NMDA receptor regulation. Nat Rev Neurosci 5:317-328.

Sanna PP, Cammalleri M, Berton F, Simpson C, Lutjens R, Bloom FE, Francesconi W (2002) Phosphatidylinositol 3-kinase is required for the expression but not for the induction or the maintenance of long-term potentiation in the hippocampal CA1 region. J Neurosci 22:3359-3365.

Shah BH, Neithardt A, Chu DB, Shah FB, Catt KJ (2006) Role of EGF receptor transactivation in phosphoinositide 3-kinase-dependent activation of MAP kinase by GPCRs. J Cell Physiol 206:47-57.

Shi SH, Hayashi Y, Petralia RS, Zaman SH, Wenthold RJ, Svoboda K, Malinow R (1999) Rapid spine delivery and redistribution of AMPA receptors after synaptic NMDA receptor activation. Science 284:1811-1816. 
Sinagra M, Verrier D, Frankova D, Korwek KM, Blahos J, Weeber EJ, Manzoni OJ, Chavis P (2005) Reelin, very-low-density lipoprotein receptor, and apolipoprotein E receptor 2 control somatic NMDA receptor composition during hippocampal maturation in vitro. J Neurosci 25:6127-6136.

Traynelis SF, Silver RA, Cull-Candy SG (1993) Estimated conductance of glutamate receptor channels activated during EPSCs at the cerebellar mossy fiber-granule cell synapse. Neuron 11:279-289.

Trommsdorff M, Borg JP, Margolis B, Herz J (1998) Interaction of cytosolic adaptor proteins with neuronal apolipoprotein $\mathrm{E}$ receptors and the amyloid precursor protein. J Biol Chem 273:33556-33560.

Trommsdorff M, Gotthardt M, Hiesberger T, Shelton J, Stockinger W, Nimpf J, Hammer RE, Richardson JA, Herz J (1999) Reeler/Disabled-like disruption of neuronal migration in knockout mice lacking the VLDL receptor and ApoE receptor 2. Cell 97:689-701.
Wang YT, Salter MW (1994) Regulation of NMDA receptors by tyrosine kinases and phosphatases. Nature 369:233-235.

Weeber EJ, Beffert U, Jones C, Christian JM, Forster E, Sweatt JD, Herz J (2002) Reelin and ApoE receptors cooperate to enhance hippocampal synaptic plasticity and learning. J Biol Chem 277:39944-39952.

Yabut O, Renfro A, Niu S, Swann JW, Marin O, D’Arcangelo G (2006) Abnormal laminar position and dendrite development of interneurons in the reeler forebrain. Brain Res Mol Brain Res, in press.

Yu XM, Askalan R, Keil II GJ, Salter MW (1997) NMDA channel regulation by channel-associated protein tyrosine kinase Src. Science 275:674-678.

Zhao S, Chai X, Forster E, Frotscher M (2004) Reelin is a positional signal for the lamination of dentate granule cells. Development 131:5117-5125.

Zhuo M, Holtzman DM, Li Y, Osaka H, DeMaro J, Jacquin M, Bu G (2000) Role of tissue plasminogen activator receptor LRP in hippocampal longterm potentiation. J Neurosci 20:542-549. 